\title{
Electrospray tandem mass spectrometric measurements of organotin compounds
}

\author{
Joseph H. Banoub *, Judith Miller-Banoub, George V. Sheppard and Howard J. Hodder \\ Department of Fisheries and Oceans, Science Branch, Special Projects, St. John's, \\ NF A1C 5X1, Canada
}

\begin{abstract}
Electrospray mass spectrometry of a series of organotin compounds in solutions of methanol are reported. Low energy collision-induced dissociation MS/MS analysis of diagnostic precursor ions confirmed the characteristic fingerprint patterns obtained in the conventional electrospray spectra and proved to be a specific and very sensitive method for quantification of the $\left(\mathrm{R}_{3} \mathrm{Sn}\right)_{2} \mathrm{O}$ and the series of $\mathrm{R}_{n} \mathrm{SnX}_{4-n}$ compounds in environmental matrices. Concentrations of butyltin compounds (TBTX, DBTX $_{2}$ and $\mathrm{MBTX}_{3}$ ) in sediment reference materials PACS-1 and PACS-2 and butyltin and phenyltin compounds (TBTX,

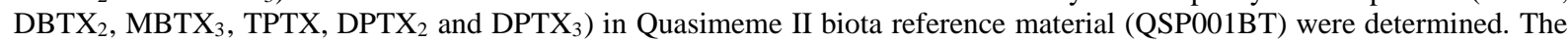
organotin compounds were extracted from the reference materials with 1-butanol followed by dilution with methanol containing $1 \mathrm{mM}$ ammonium acetate. The extracts were introduced directly into the electrospray source by a continuous flow of $\mathrm{MeOH}: \mathrm{H}_{2} \mathrm{O}(60: 40)$. Quantitation of TBTX, DBTX 2 , TPTX, DPTX 2 and DPTX 3 was achieved by low energy CID tandem mass spectrometry using the Multiple Reaction Monitoring (MRM) analysis with the appropriate MS/MS transitions (positive ion electrospray ionization). Quantitation of $\mathrm{MBTX}_{3}$ was achieved using a negative ion electrospray CID tandem mass spectrometry method. For all samples quantitation was achieved by use of the method of standard addition, relative extraction recoveries were determined spiking with internal standards of mono-, di- and triorganotin compounds separately to different samples.
\end{abstract}

\section{Introduction}

Antifouling paints inhibit or prevent the growth of plant and animal organisms on moving or static objects immersed in water. Fouling causes significant losses for the shipping industry [1,2]. In the case of ships, more fuel is required to overcome the higher resistance caused by the adherence of barnacles on the ship's hull, whereas for static parts such as drilling platforms, severe displacement of equilibrium can occur. An effective antifouling paint is derived from a combination of different active substances to prevent the growth of the widest possible spectrum of organisms. Organotin biocides having the general formula $\mathrm{R}_{n} \mathrm{SnX}_{4-n}$, especially triorganotin compounds having the structure $\mathrm{R}_{3} \mathrm{SnX}$ and $\left(\mathrm{R}_{3} \mathrm{Sn}\right)_{2} \mathrm{O}$, have been widely used in the formulations of antifouling agents in some paints for boats, ships and docks, and have been found in waters with heavy boating and shipping traffic [3]. Tributyltin compounds have been widely used as industrial biocides, whereas triphenyltin and tricyclohexyltin derivatives have found large scale applications as agricultural fungicides and miticides, respectively. Monoorganotin $\left(\mathrm{RSnX}_{3}\right)$ and diorganotin $\left(\mathrm{R}_{2} \mathrm{SnX}_{2}\right)$ compounds have also been used in a different variety of applications including polyvinyl chloride (PVC) stabilizers [4]. The worldwide production of organotin compounds, consequently, has witnessed a dramatic increase. The organotin compounds, in particular tributyl- and triphenyltin compounds, are known to be extremely toxic towards aquatic organisms and mammals [5]. As these compounds accumulate in the aquatic environment and sediments, there is an ongoing concern about their environmental fate and the effect on non-target organisms. Under favorable conditions, the accumulated species can be released into the aquatic environment and create an ecotoxicological risk even after banning of the anthropogenic sources from the given area [6,7].

\footnotetext{
${ }^{*}$ Corresponding author.
} 
In the Canadian marine environment, these compounds were responsible for the decreasing populations of Pacific oysters and for causing imposex and intersex defects in the neogastropods, which are of growing economical concern $[8,9]$. As a result of this ecotoxicological risk, the use of TBT compounds as an antifoulant has now been banned in many countries [10]. The high toxicity of the organotin compounds to non-target organisms necessitates highly sensitive analytical protocols to quantify the potentially toxic concentrations $(<2 \mathrm{mg} / \mathrm{l})$ [5]. A variety of analytical techniques have been developed for the detection and quantitation of tri-substituted organotin compounds and their degradation products such as monoand dibutyl- and phenyltin in sediments [11].

Despite the increased popularity of high performance liquid chromatography-inductively coupled plasma mass spectrometry (HPLC-ICP-MS) [12], the coupling of gas chromatography (GC) to atomic absorption spectrometry (AAS) [13], flame photometric detection (FPD) [14], microwave-induced plasma atomic absorption (MIP-AES) [15] and to mass spectrometry (GC-MS) [16-19] remain the preferred choices. The main drawback of all these gas chromatographic methods is the omnipresent need for separation of the analyte species from the matrix and conversion into a form that is acceptable for presentation to the chromatographic column [11]. Usually, derivatization to increase the volatility of the organotin analytes can be accomplished either via hydridization with sodium borohydride or ethylation with sodium tetraethylborate [20]. Another method for increasing the volatility of the organotin analytes, which has gained popularity, is based on a Grignard trans-alkylation reaction which leads to the formation of the tetrasubstituted tin derivative [21]. Recently, methods based on supercritical fluid extraction (SFE) procedures, following in situ derivatization, were reported for the determination of butyl compounds in sediments [22].

Although the previous methods had their merits, they are laborious and time consuming, requiring extensive work-up including extraction, clean-up and derivatization. We have investigated the use of electrospray mass spectrometry (ES MS), arguably, one of the softest ionization methods, to measure a series of organotin compounds. This method requires neither derivatization nor excessive manipulation of the mostly polar and non-volatile organotin analytes which are usually present as ions in the solution to be analyzed. Electrospray ionization is well established as a robust technique for use with combined liquid chromatography/mass spectrometry (LC/MS) which allows the rapid and sensitive analysis of a wide range of analytes from low molecular mass polar compounds $(<200 \mathrm{Da})$ to biopolymers $(>100 \mathrm{kDa})$ [23].

As a continuation of our interest in the MS and MS/MS of toxic chemicals [24-29], we now report on the structural characterization and quantitation, using ES MS, of polar organotin compounds, specifically bis-tributyltin oxide, $(\mathrm{TBT})_{2} \mathrm{O}, \underline{1}$, tributyltin chloride $\underline{2}$, dibutyltin dichloride $\underline{3}$, monobutyltin trichloride $\underline{4}$, triphenyltin chloride $\underline{5}$, diphenyltin dichloride $\underline{6}$ and monophenyltin trichloride $\underline{7}$. Confirmation of the structural identity of these compounds was also effected from low energy MS/MS analysis of diagnostic fragments derived from the precursor ions.

\section{Materials and methods}

\subsection{Reagents and reference sediments}

Organotin compounds (99.9\% purity) were purchased from Sigma-Aldrich Canada Ltd. PACS-1 and PACS-2 sediments with a certified content of butyltin compounds (TBTX, DBTX 2 and MBTX $_{3}$ ) were obtained from the National Research Council of Canada, Ottawa, Ontario. Quasimeme II biota reference 
material QSP001BT containing the $\mathrm{R}_{n} \mathrm{SnX}_{4-n}$ series of organotin compounds (TBTX, DBTX ${ }_{2}, \mathrm{MBTX}_{3}$, TPTX, DPTX 2 and MPTX 3 ) was purchased from Quasimeme, Aberdeen, UK. The biota reference material was not certified, however, the organotin concentrations have been determined in an inter-laboratory test.

\subsection{Extraction}

$4 \mathrm{~g}$ of PACS or QSP001BT was placed in a $50 \mathrm{ml}$ centrifuge tube together with $8 \mathrm{ml}$ of 1-butanol. The suspension was sonicated for $1 \mathrm{~h}$ and centrifuged at about $2000 \mathrm{rpm}$ for $10 \mathrm{~min}$. For organotin compounds $\underline{1}-\underline{3}$ and $\underline{5}-\underline{7}$, the 1-butanol phase was removed and $1 \mathrm{ml}$ of it was subsequently diluted to $25 \mathrm{ml}$ with methanol containing $1 \mathrm{mM}$ ammonium acetate [30]. In the case of $\mathrm{MBTX}_{3}, \underline{4}$, the 1-butanol phase was removed and $1 \mathrm{ml}$ was diluted to $25 \mathrm{ml}$ with methanol containing $1 \%$ triethylamine.

\subsection{Mass spectrometric conditions}

The ESI mass spectra were recorded with a Micromass Quattro quadrupole-hexapole-quadrupole mass spectrometer equipped with a megaflow ESI source and capable of analyzing ions up to $m / z 4000$. A personal computer (Compaq PIII, $550 \mathrm{MHz}$ processor, running Windows NT 4, service pack 5) equipped with Micromass MASSLYNX 3.2.0 Mass Spectrometry Data System software was used for data acquisition and processing. The temperature of the ESI source was maintained at $75^{\circ} \mathrm{C}$. The operating voltage of the ESI capillary was $3.00 \mathrm{kV}$ and the high voltage lens was set at $0.40 \mathrm{kV}$ throughout the whole operation. ESI-MS were recorded with focus voltages varying from 18 to $70 \mathrm{~V}$. The standard solutions used for ES MS and MS/MS were prepared with HPLC solvent grade methanol at varying concentrations of $1.25 \mathrm{pg}-\mathrm{ml}^{-1}$ to $80 \mathrm{pg}-\mathrm{ml}^{-1}$. A $20 \mu \mathrm{l}$ aliquot of sample was introduced into the electrospray ionization source at a flow rate of $100 \mu \mathrm{l}-\mathrm{min}^{-1}$ using a Shimadzu LC-10AD pump connected to the Rheodyne injector with a $20 \mu \mathrm{l}$ loop. The mobile phase was a mixture of HPLC solvent grade methanol: water $(60: 40)$. MS/MS experiments were conducted using the same instrument. Fragment ion spectra of massselected ions were induced by collision with argon in the (r.f.-only) hexapole. The resulting fragment ions were analyzed by the second quadrupole.

\subsection{Calibrations, determination of absolute and relative recoveries and method detection limits}

The linearities of all the MRM CID-tandem mass spectrometric analyses conducted for this series of standard organotin compounds were tested at concentrations ranging from $1 \mathrm{ng}-\mathrm{ml}^{-1}$ to $80 \mathrm{ng}-\mathrm{ml}^{-1}$. Calibration curves were linear with coefficients of determination $r^{2}>0.999$. For sediment samples quantitation was achieved by use of the method of standard addition, relative extraction recoveries were determined by spiking with internal standards of mono-, di- and triorganotin compounds separately to different samples. For absolute extraction recoveries, internal standards were added to the methanolic dilution before extraction. The method detection limit (MDL) was defined as three times the standard deviation of the lowest concentration.

\section{Results and discussion}

Combined gas chromatography and mass spectrometry (GC-MS) is probably one of the most specific methods for characterization and quantification of traces of volatile contaminants from complex environmental matrices. On the other hand, HPLC-MS is a perfect method for the identification of non-volatile 
analytes [16-19]. Recently, HPLC-MS using electrospray ionization has been used to study the behavior of organotin compounds of the general formula $\mathrm{R}_{n} \mathrm{SnX}_{4-n}$ [31]. Detection of organotin ions was enhanced by the use of acetic acid in the methanol mobile phase and the formation of adduct ions and reaction products involving the solvent were noted [32].

Analysis of selected organotin analytes was also performed using HPLC-MS with a particle beam interface ionization chamber in which the resulting mass spectra matched conventional electron-impact ionization spectra obtained by probe insertion in the mass spectrometer [33]. These investigations did not directly address the problem of minimum detection levels appropriate for environmental analyses or involved low energy collisional tandem mass spectrometric analysis used for quantitative applications [31-33].

Siu and co-workers used liquid chromatography-ionspray mass spectrometry (LC-IS-MS) to quantify tributyltin in a sediment reference material (PACS-1) having a minimum detectable amount in the low picogram range [30,34,35].

The analysis of the electrospray mass spectra of the alkyltin chloride $\mathrm{R}_{n} \mathrm{SnX}_{4-n}$ compounds is complicated by the presence of mixed isotopic contributions to the mass of the studied ions. Tin has five major isotopes and two chlorine isotopes which introduce a variety of differences in the mass for the same chemical structure, especially if we are dealing with these chlorine tin-containing ions. The $m / z$ values discussed have been assigned on the basis of ${ }^{120} \mathrm{Sn}$ and ${ }^{35} \mathrm{Cl}$, which are the most abundant isotopes.

The electrospray mass spectrum (positive ion mode) of bis-tributyltin oxide (1) was recorded using a low focus voltage $(25 \mathrm{~V})$ and gave only a major monocharged ion corresponding to the protonated molecule $[\mathrm{M}+\mathrm{H}]^{+}$centered at $m / z 599$. The electrospray mass spectrum of bis-tributyltin oxide, shown in Fig. 1A, is identical to the calculated isotopic distribution of tin in the $[\mathrm{M}+\mathrm{H}]^{+}$protonated molecule (Fig. 1B). To generate more structural information, the dissociation of the $[\mathrm{M}+\mathrm{H}]^{+}$ion was prompted by varying the accelerating voltage $(0 \pm 250 \mathrm{~V})$ applied to the sampling focus (focus voltage) of the electrospray source. This procedure is also referred to as collision induced dissociation (CID) in the atmospheric pressure/vacuum interface or focus voltage fragmentation. To obtain more substantial structural information, we have recorded the electrospray mass spectra of 1 with two different higher focus voltages ( 35 and $50 \mathrm{~V}$ ) as shown in Figs $2 \mathrm{~A}$ and $2 \mathrm{~B}$, respectively.

In the ES MS of 1 recorded with a focus voltage of $35 \mathrm{~V}$, Fig. $2 \mathrm{~A}$, we noticed the formation of three new ions designated as $\left[\mathrm{Bu}_{3} \mathrm{Sn}\right]^{+},\left[\mathrm{Bu}_{2} \mathrm{SnH}\right]^{+}$and $\left[\mathrm{BuSnH}_{2}\right]^{+}$at $m / z 291,235$ and 178, respectively.

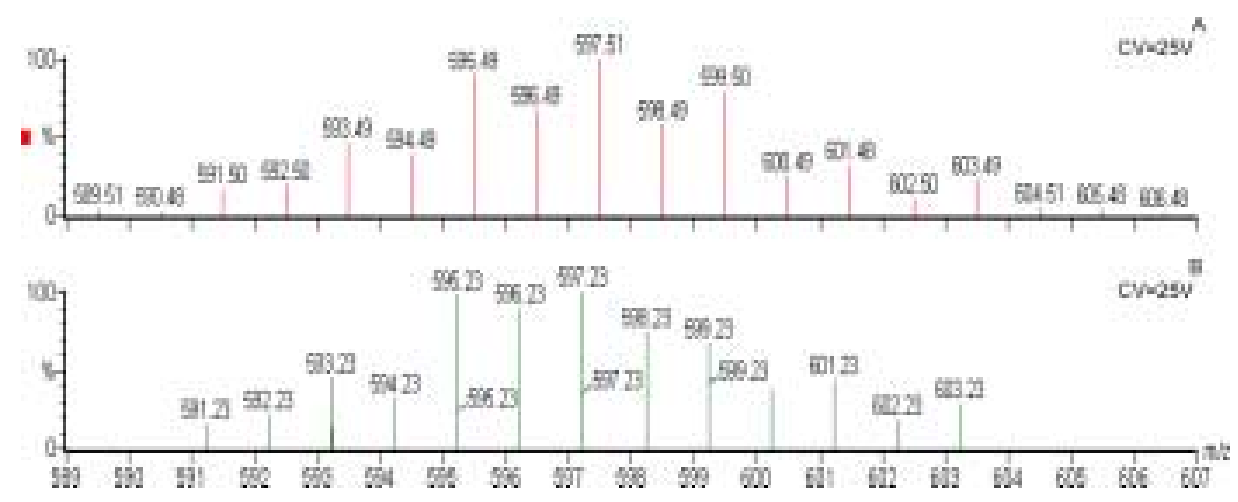

Fig. 1. Electrospray mass spectra (positive ion mode) of bis-tributyltin oxide 1 recorded with a focus voltage of $25 \mathrm{~V}$ showing the isotopic distribution of the $[\mathrm{M}+\mathrm{H}]^{+}$protonated molecule (A); calculated ES MS isotopic distribution of the protonated molecule (B). 


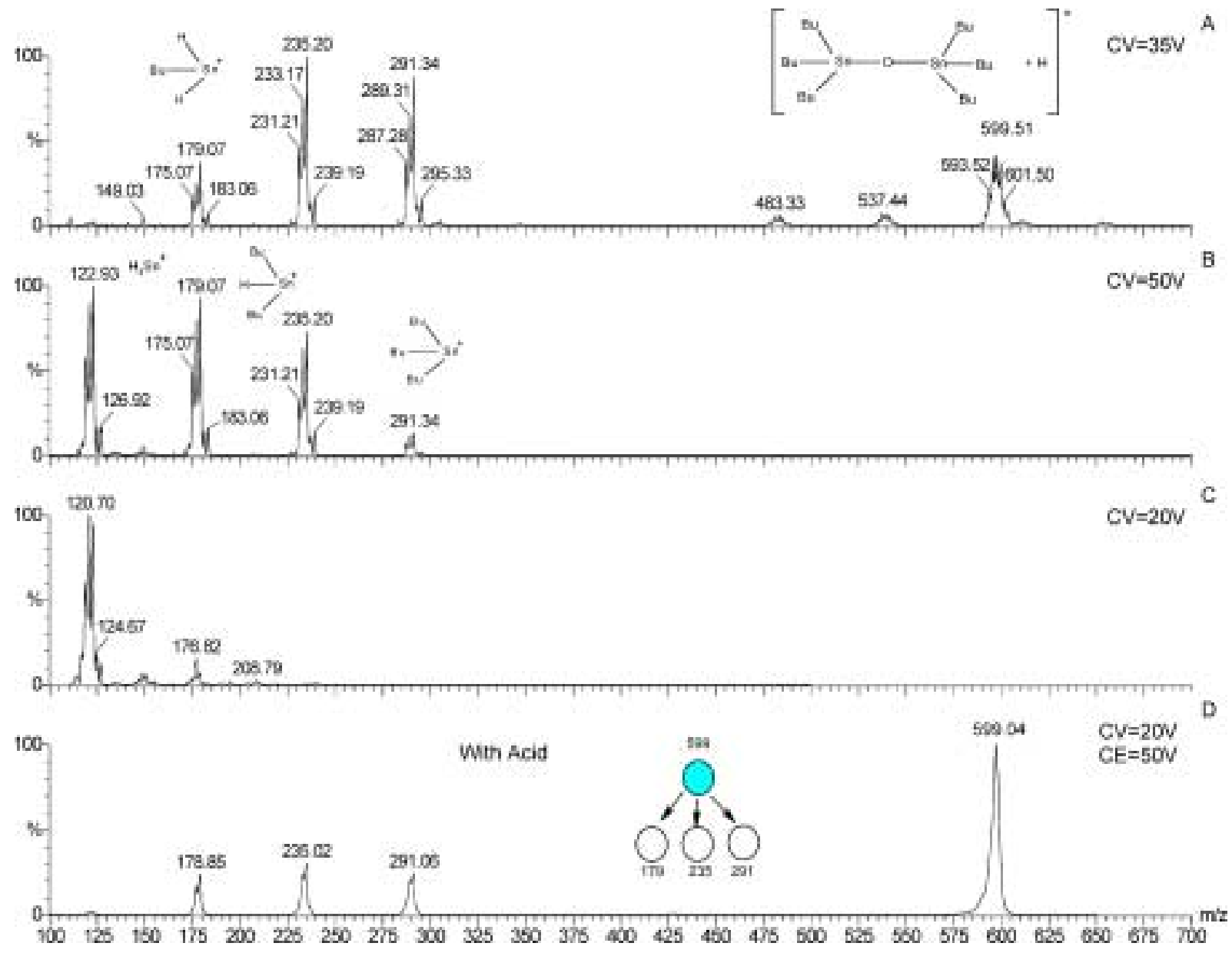

Fig. 2. Electrospray mass spectra of bis-tributyltin oxide 1 recorded with different focus voltages: $\mathrm{CV}=35 \mathrm{~V}(\mathrm{~A}), \mathrm{CV}=$ $50 \mathrm{~V}(\mathrm{~B})$ and $\mathrm{CV}=20 \mathrm{~V}$ after treatment with a trace of $6 \mathrm{M} \mathrm{HCl}$ and CID tandem mass spectrum of the protonated molecule $[\mathrm{M}+\mathrm{H}]^{+}$at $m / z 599(\mathrm{D})$.

The fragment ion at $m / z 291$ was assigned as $\left[\mathrm{Bu}_{3} \mathrm{Sn}\right]^{+}$and was produced by fragmentation of the protonated molecule $[\mathrm{M}+\mathrm{H}]^{+}$. The fragment ions $\left[\mathrm{Bu}_{2} \mathrm{SnH}\right]^{+}$and $\left[\mathrm{BuSnH}_{2}\right]^{+}$at $m / z 235$ and 179 are most likely produced via loss of either one or two molecules of butene from the precursor $\left[\mathrm{Bu}_{3} \mathrm{Sn}\right]^{+}$ion at $m / z 291$.

In the ES MS of 1, recorded with a focus voltage of $50 \mathrm{~V}$ (Fig. 2B), we noticed the complete dissociation of the protonated molecule $[\mathrm{M}+\mathrm{H}]^{+}$at $m / z 597$, the increased dissociation of the $\left[\mathrm{Bu}_{3} \mathrm{Sn}\right]^{+}$ion at $m / z 291$ and the appearance of the $\left[\mathrm{SnH}_{3}\right]^{+}$ion at $\mathrm{m} / z 123$ which is formed via loss of three molecules of butene from the precursor ion $\left[\mathrm{Bu}_{3} \mathrm{Sn}\right]^{+}$at $m / z 291$.

In order to investigate the effect of acid on the ES MS of bis-tributyltin oxide we recorded the ES MS of 1 in the presence of traces of acids such as concentrated $(6 \mathrm{M})$ and dilute $(2 \mathrm{M})$ hydrochloric acid (Fig. 2C). This showed the complete degradation of the protonated molecule $[\mathrm{M}+\mathrm{H}]^{+}$and the derived fragment ions $\left[\mathrm{Bu}_{3} \mathrm{Sn}\right]^{+},\left[\mathrm{Bu}_{2} \mathrm{SnH}\right]^{+}$and $\left[\mathrm{BuSnH}_{2}\right]^{+}$at $\mathrm{m} / z$ 597, 291, 235 and 179, respectively. The base peak of this ES MS is the $\left[\mathrm{SnH}_{3}\right]^{+}$at $m / z 123$ which was produced by the instantaneous removal of all butene molecules from the precursor ions. It is worthwhile to mention that organotin compound 
extraction methods reported in the literature involve an acidification with either concentrated or dilute $\mathrm{HCl}$.

Low energy MS/MS analyses were conducted to rationalize the pathway leading to the various fragmentations observed in the conventional electrospray mass spectra obtained by adjustment of the accelerating voltage ( 35 to $50 \mathrm{~V}$ ) applied to the sampling focus of the electrospray source. Product ion spectra arising from fragmentation in the hexapole collision cell of the quadrupole-hexapole-quadrupole instrument were obtained. The product ion spectrum arising from the fragmentation of the protonated molecule at $m / z 597$ in the RF-hexapole collision cell is presented in Fig. 2D. This CID tandem mass spectrum confirms the formation of the series of product ions at $m / z 291,235$ and 179 whose formation has been tentatively rationalized above. A significant advantage of the MS/MS technique is that it eliminates all uncertainty as to the origin of the fragment ions and it establishes the connectivities between these ions $[36,37]$.

The electrospray mass spectra of tributyltin chloride $\underline{2}$ were recorded using a series of focus voltages of 15, 25 and $50 \mathrm{~V}$, as shown in Fig. 3. As expected, the ES MS recorded with a focus voltage of $15 \mathrm{~V}$ did not show the presence of the protonated molecule $[\mathrm{M}+\mathrm{H}]^{+}$at $m / z 325$, but contained the fragment ion at $m / z 291$ arising from the loss of a molecule of hydrogen chloride from the theoretical

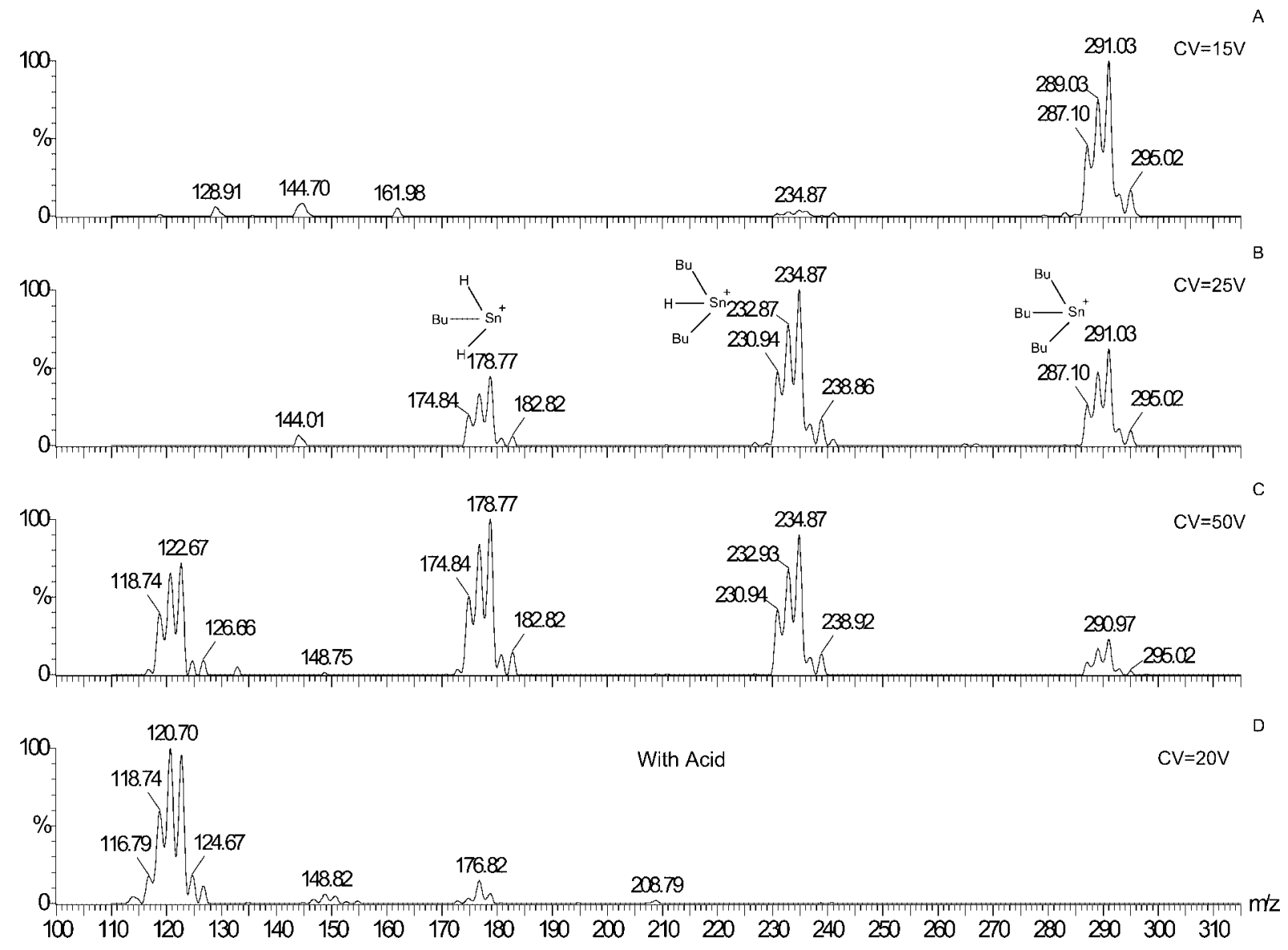

Fig. 3. Electrospray mass spectra of tributyltin chloride $\underline{2}$ recorded with different focus voltages: $\mathrm{CV}=15 \mathrm{~V}(\mathrm{~A}), \mathrm{CV}=25 \mathrm{~V}$ (B) and $\mathrm{CV}=50 \mathrm{~V}(\mathrm{C})$ and $\mathrm{CV}=20 \mathrm{~V}$ after treatment with a trace of $6 \mathrm{M} \mathrm{HCl}$ (D). 
$[\mathrm{M}+\mathrm{H}-\mathrm{HCl}]^{+}$fragment ion and was assigned as the $\left[\mathrm{Bu}_{3} \mathrm{Sn}\right]^{+}$structure (Fig. 3A). The ES MS recorded with a focus voltage of $25 \mathrm{~V}$ afforded a series of diagnostic fragment ions arising from the losses of one or two molecules of butene from the fragment ion $\left[\mathrm{Bu}_{3} \mathrm{Sn}\right]^{+}$at $m / z 291$. This ion loses either a molecule of butene $(56 \mathrm{Da})$ to afford the $\left[\mathrm{Bu}_{3} \mathrm{Sn}^{+}-\mathrm{C}_{4} \mathrm{H}_{8}\right]^{+}$ion at $m / z 235$ assigned as $\left[\mathrm{Bu}_{2} \mathrm{SnH}\right]^{+}$or two molecules of butene to afford the $\left[\mathrm{Bu}_{3} \mathrm{Sn}^{+}-2\left(\mathrm{C}_{4} \mathrm{H}_{8}\right)\right]^{+}$ion at $m / z 179$ assigned as $\left[\mathrm{BuSnH}_{2}\right]^{+}$and shown in Fig. 3B. The ES MS recorded with a focus voltage of $50 \mathrm{~V}$ showed the same series of diagnostic fragment ions at $m / z 291,235$ and 179 , and a newly formed fragment ion at $m / z 123$. This latter was assigned as the $\left[\mathrm{Bu}_{3} \mathrm{Sn}^{+}-3\left(\mathrm{C}_{4} \mathrm{H}_{8}\right)\right]^{+}$or $\left[\mathrm{SnH}_{3}\right]^{+}$fragment ion (Fig. 3C).

Similarly, as in the case of bis-tributyltin oxide $\underline{1}$, the ES MS of $\underline{2}$ was recorded in the presence of a catalytic amount of hydrochloric acid $(2 \mathrm{M})$ and, once more, instantaneous removal of all butene molecules from the precursor ions at $m / z 291,235$ and 179 was observed, with the formation of the base peak $\left[\mathrm{SnH}_{3}\right]^{+}$at $m / z 123$ (Fig. 3D).

The CID tandem mass spectrum of the fragment ion $\left[\mathrm{Bu}_{3} \mathrm{Sn}\right]^{+}$at $m / z 291$, shown in Fig. 4A, confirmed the formation of the product ions originally obtained in the conventional mass spectrum recorded with a focus voltage of $25 \mathrm{~V}$ and afforded the fragment ions $\left[\mathrm{Bu}_{2} \mathrm{SnH}\right]^{+}$and $\left[\mathrm{BuSnH}_{2}\right]^{+}$at $m / z 235$ and 179 , respectively. Second generation product ions of the intermediate fragment ion at $m / z 235$ afforded

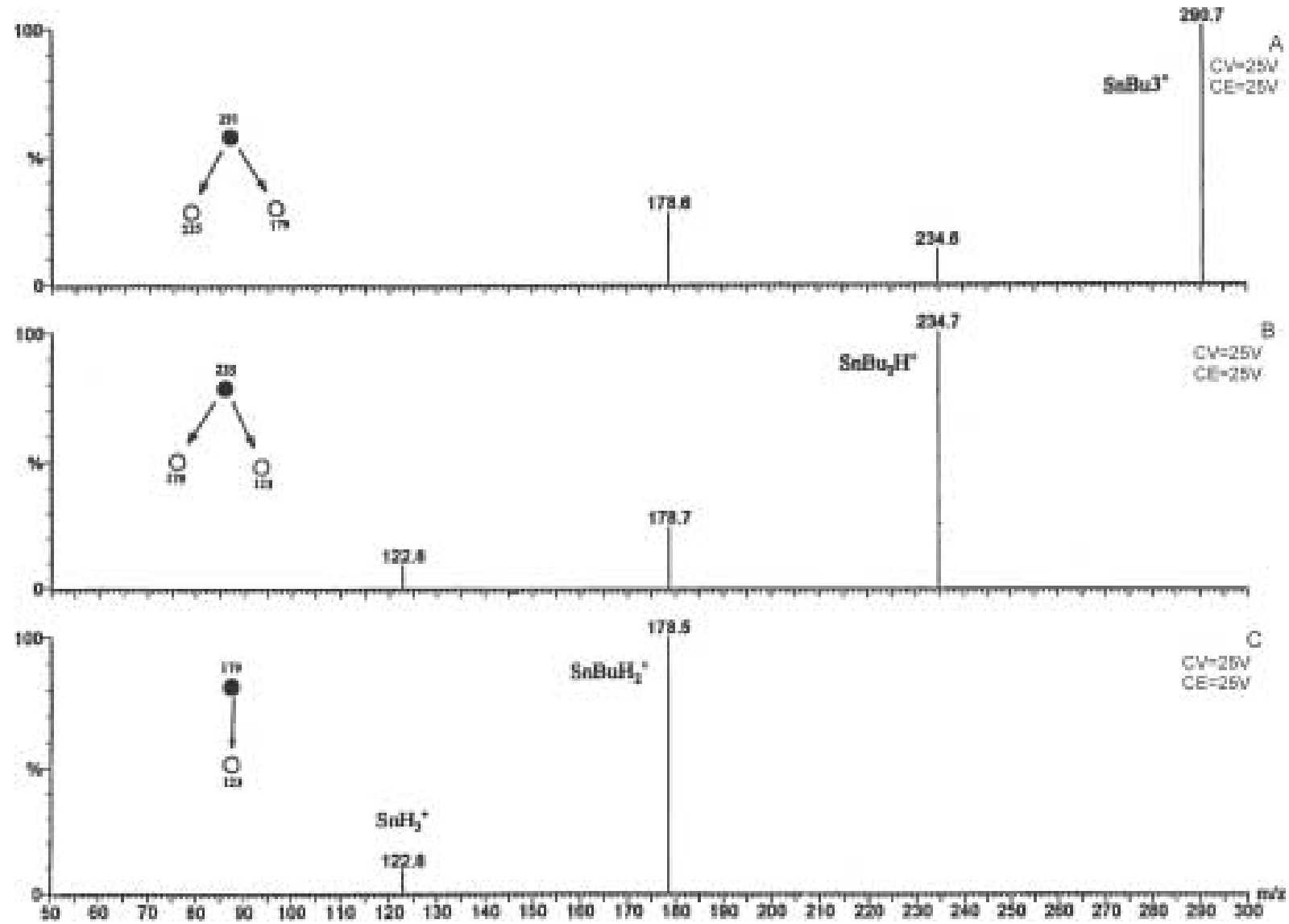

Fig. 4. CID tandem mass spectrum of $\left[\mathrm{Bu}_{3} \mathrm{Sn}\right]^{+}$at $m / a 291$ recorded with a $\mathrm{CV}=25 \mathrm{~V}$ and $\mathrm{CE}=25 \mathrm{~V}$ (A); $\mathrm{CID} \mathrm{ms} / \mathrm{ms}$ of $\left[\mathrm{Bu}_{2} \mathrm{SnH}\right]^{+}$at $m / z 235$, recorded with a $\mathrm{CV}=25 \mathrm{~V}$ and $\mathrm{CE}=25 \mathrm{~V}(\mathrm{~B}) ; \mathrm{CID} \mathrm{MS} / \mathrm{MS}$ of $\left[\mathrm{BuSnH}_{2}\right]^{+}$at $m / z 179 \mathrm{recorded}$ with a $\mathrm{CV}=25 \mathrm{~V}$ and $\mathrm{CE}=25 \mathrm{~V}(\mathrm{C})$. 
the product ions at $m / z 179$ and 123 , resulting from the simultaneous losses of one or two molecules of butene from the $\left[\mathrm{Bu}_{2} \mathrm{SnH}\right]^{+}$ion (Fig. $4 \mathrm{~B}$ ). Third generation product ions of the intermediate fragment ion at $\mathrm{m} / z 179$ afforded the product ion $\left[\mathrm{SnH}_{3}\right]^{+}$at $\mathrm{m} / z 123$ resulting from the loss of the last butene molecule from the $\left[\mathrm{BuSnH}_{2}\right]^{+}$ion (Fig. 4C). This series of CID tandem mass spectra shown in Fig. 4 indicates that the loss of butene molecules from the fragment $\left[\mathrm{Bu}_{3} \mathrm{Sn}\right]^{+}$ion at $\mathrm{m} / z 291$ can happen, not only by a concerted mechanism, but also in a step by step mode. This last observation was confirmed once more by obtaining the precursor ion scans of the fragment ions $\left[\mathrm{SnH}_{3}\right]^{+},\left[\mathrm{BuSnH}_{2}\right]^{+}$and $\left[\mathrm{Bu}_{2} \mathrm{SnH}\right]^{+}$at $m / z 123,179$ and 235, respectively as shown in Fig. 5.

The precursor ion scan of the $\left[\mathrm{SnH}_{3}\right]^{+}$fragment ion at $\mathrm{m} / z 123$ indicated that it originated from the $\left[\mathrm{BuSnH}_{2}\right]^{+},\left[\mathrm{Bu}_{2} \mathrm{SnH}\right]^{+}$and $\left[\mathrm{Bu}_{3} \mathrm{Sn}\right]^{+}$fragment ions at $m / z 179,235$ and 291, respectively (Fig. 5A). The precursor ion scan of the $\left[\mathrm{BuSnH}_{2}\right]^{+}$fragment ion at $m / z 179$ indicated that it originated from both the $\left[\mathrm{Bu}_{2} \mathrm{SnH}\right]^{+}$and $\left[\mathrm{Bu}_{3} \mathrm{Sn}\right]^{+}$fragment ions at $m / z 235$ and 291, respectively (Fig. 5B). Finally, the precursor ion scan of the $\left[\mathrm{Bu}_{2} \mathrm{SnH}\right]^{+}$fragment ion at $m / z 235$ indicated that it originated from the $\left[\mathrm{Bu}_{3} \mathrm{Sn}\right]^{+}$fragment ion at $m / z 291$ (Fig. 5C).

Contrary to the initial study done by ionspray mass spectrometry, which could not measure dibutyltin dichloride as the sensitivity was reportedly too low, the electrospray mass spectrum of dibutyltin dichloride $\underline{3}$ was recorded with a focus voltage of $25 \mathrm{~V}$ and showed the protonated molecule $[\mathrm{M}+\mathrm{H}]^{+}$at $m / z$

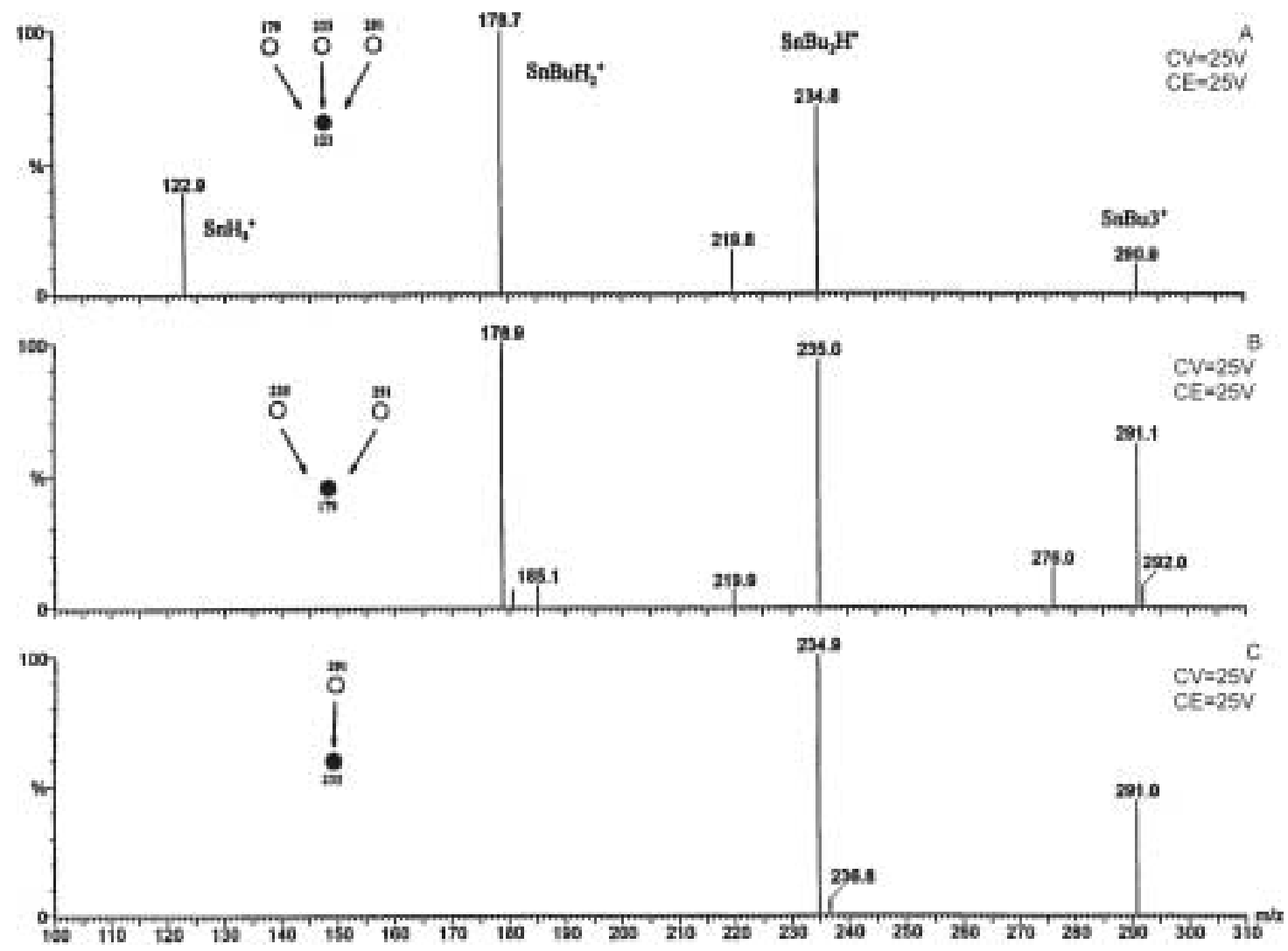

Fig. 5. Precursor ion scans of the $\left[\mathrm{SnH}_{3}\right]^{+}$ion at $m / z 123$ (A); $\left[\mathrm{BuSnH}_{2}\right]^{+}$at $m / z 179$ (B) and $\left[\mathrm{Bu}_{2} \mathrm{SnH}^{+} m / z 235\right.$ (C) recorded with a $\mathrm{CV}=25 \mathrm{~V}$ and $\mathrm{CE}=25 \mathrm{~V}$. 


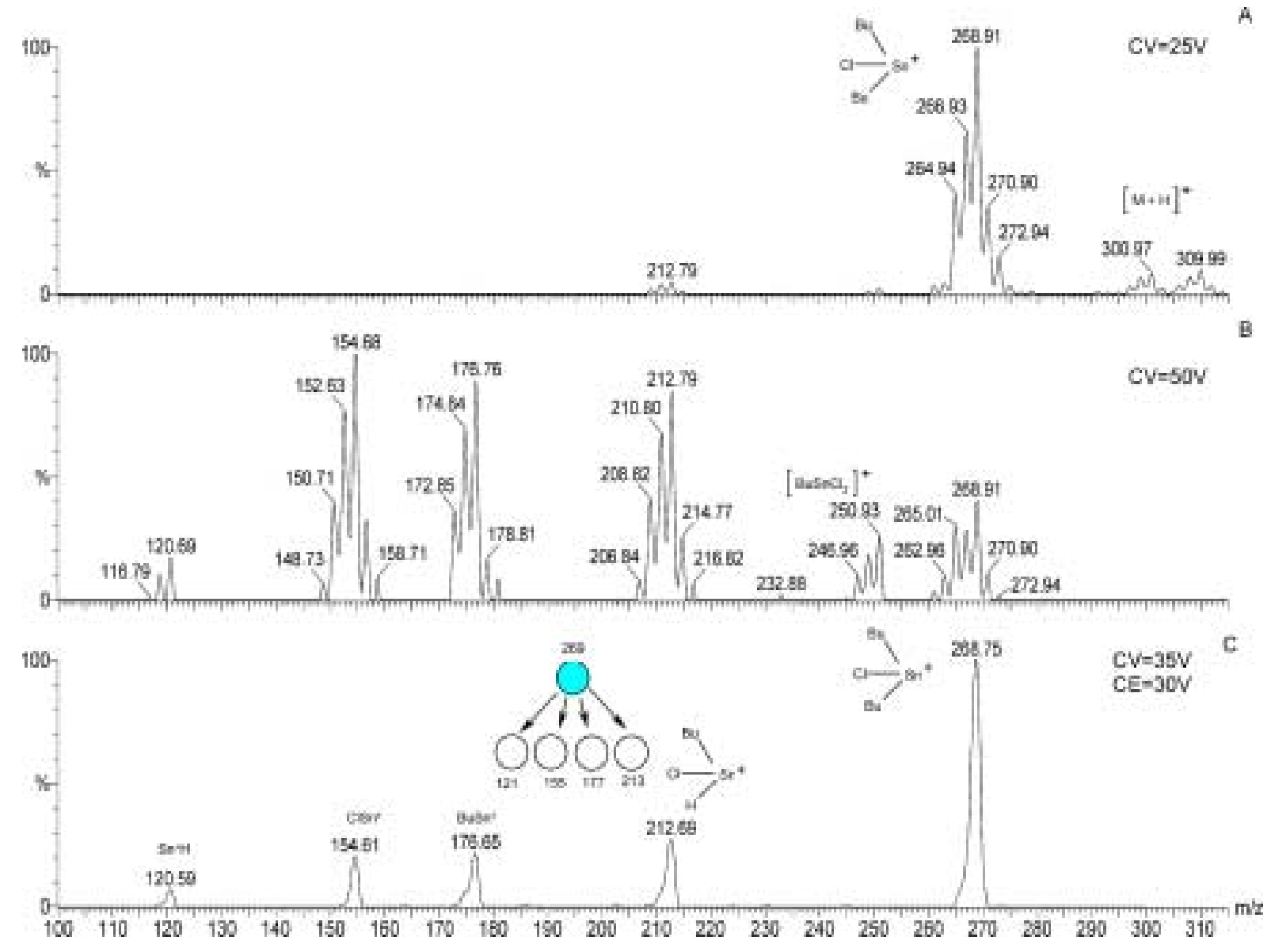

Fig. 6. Electrospray mass spectra (positive ion mode) of dibutyltin dichloride 3 recorded with different focus voltages: $\mathrm{CV}=$ $25 \mathrm{~V}(\mathrm{~A}), \mathrm{CV}=50 \mathrm{~V}(\mathrm{~B})$ and $\mathrm{CID}$ tandem mass spectrum of the $\left[\mathrm{Bu}_{2} \mathrm{SnCl}\right]^{+}$ion at $m / z 269$ recorded with a $\mathrm{CV}=35 \mathrm{~V}$ and $\mathrm{CE}=30 \mathrm{~V}(\mathrm{C})$.

306 and the fragment ion $[\mathrm{M}+\mathrm{H}-\mathrm{HCl}]^{+}$at $m / z 269$, formed by the loss of $\mathrm{HCl}$ from the protonated molecule, which was assigned as $\left[\mathrm{Bu}_{2} \mathrm{SnCl}\right]^{+}$and is shown in Fig. 6A.

The ES MS of $\underline{3}$, recorded with a focus voltage of $50 \mathrm{~V}$, shown in Fig. $6 \mathrm{~B}$, indicates a series of diagnostic ions derived from the protonated molecule. The fragment ion $\left[\mathrm{M}+\mathrm{H}-\mathrm{C}_{4} \mathrm{H}_{8}\right]^{+}$at $m / z 251$ was produced by the loss of a molecule of butene $(56 \mathrm{Da})$ from the protonated molecule and was assigned as $\left[\mathrm{BuSnCl}_{2}\right]^{+}$. The fragment ion $\left[\mathrm{M}+\mathrm{H}-\mathrm{HCl}-\mathrm{C}_{4} \mathrm{H}_{8}\right]^{+}$at $m / z 213$ was formed by the loss of a molecule of butene $(56 \mathrm{Da})$ from the $\left[\mathrm{Bu}_{2} \mathrm{SnCl}\right]^{+}$ion and was assigned as $[\mathrm{BuSnHCl}]^{+}$. The fragment ion $[\mathrm{M}+\mathrm{H}-$ $\left.\mathrm{HCl}-\mathrm{C}_{4} \mathrm{H}_{8}-\mathrm{HCl}\right]^{+}$at $m / z 177$ was formed by loss of a molecule of $\mathrm{HCl}(36.5 \mathrm{Da})$ from the [BuSnHCl$]^{+}$ fragment ion at $m / z 213$ and was assigned as $[\mathrm{BuSn}]^{+}$. The fragment ion at $m / z 155$ is formed by the loss of two butyl groups (114 Da) from the $\left[\mathrm{Bu}_{2} \mathrm{SnCl}\right]^{+}$at $m / z 269$ and was assigned as $[\mathrm{SnCl}]^{+}$. Finally, the fragment ion at $m / z 121$ is produced by the loss of one molecule of butene from the [BuSn] ${ }^{+}$ fragment ion at $m / z 177$ and was assigned as the tin hydride ion $[\mathrm{SnH}]^{+}$.

The CID tandem mass spectrum of the $\left[\mathrm{Bu}_{2} \mathrm{SnCl}\right]^{+}$ion at $m / z 269$, shown in Fig. 6C, indicates that the product ion $[\mathrm{BuHSnCl}]^{+}$at $m / z 213$ is obtained by the loss of one molecule of butene from this parent ion. The product ion [BuSn] $]^{+}$at $m / z 177$ is obtained either by the loss of one molecule of butyl chloride 
(92 Da) from the parent ion, or by the loss of a molecule of $\mathrm{HCl}$ from the product ion $[\mathrm{BuHSnCl}]^{+}$at $m / z 213$. The product ion $[\mathrm{SnCl}]^{+}$at $m / z 155$ is obtained by the consecutive losses of two molecules of butene $(112 \mathrm{Da})$ from the parent ion. Finally, the product ion $[\mathrm{SnH}]^{+}$is produced by the loss of two molecules of butene and one molecule of $\mathrm{HCl}$ from the parent ion. This CID tandem mass spectrum confirms the origin of this series of product ions and rationalizes their formation in the conventional ES MS. It is interesting to note that the series of product ions $[\mathrm{BuSn}]^{+},[\mathrm{SnCl}]^{+}$and $[\mathrm{SnH}]^{+}$at $m / z 177$, 155 and 121, respectively, produced during the conventional electrospray mass spectrum or CID tandem mass spectrum, have undergone a reduction during fragmentation, from a tetravalent (tetrahedral) tin cation to a divalent (planar) tin cation.

We were not successful in obtaining a reproducible electrospray of monobutyltin trichloride in the positive mode. However, when it was electrosprayed in the negative mode in a solution of methanol containing a catalytic amount of triethylamine, a characteristic mass spectrum was produced and is shown in Fig. 7A. In this ES MS, we notice the presence of the deprotonated molecular adduct $[\mathrm{M}+\mathrm{MeOH}-\mathrm{H}]^{+}$ cluster centered at $m / z 317$ (for ${ }^{120} \mathrm{Sn}$ ) which was formed by the addition of one molecule of methanol. The base peak cluster which is centered at $m / z 225$ is produced from the deprotonated molecular adduct

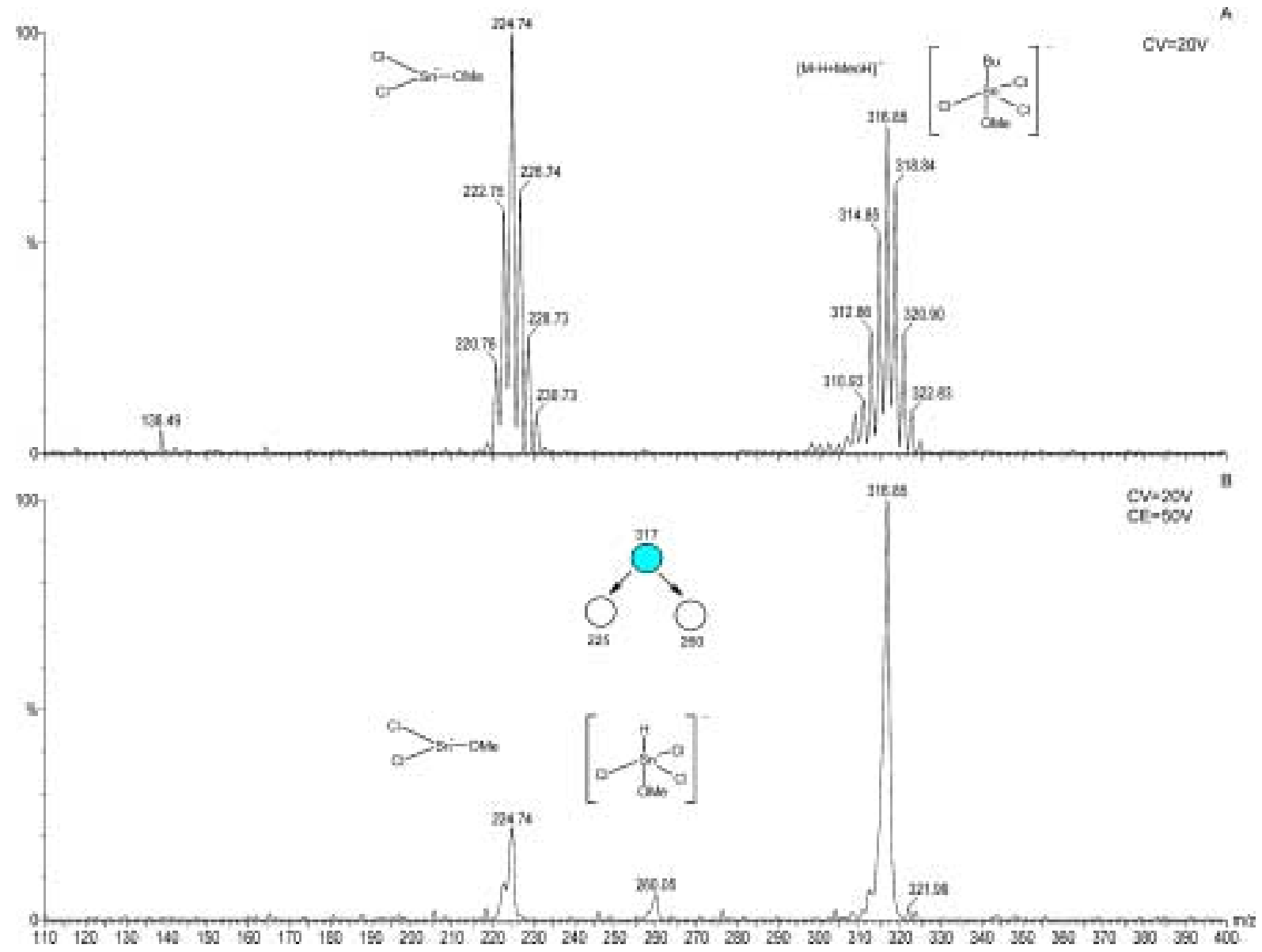

Fig. 7. Electrospray mass spectrum (negative ion mode) of monobutyltin trichloride $\underline{4}$ recorded with a CV $=20 \mathrm{~V}$ (A) and CID tandem mass spectrum of the deprotonated molecular adduct $[\mathrm{M}+\mathrm{MeOH}-\mathrm{H}]^{-}$at $m / z 317$ (B). 
by loss of a molecule of butyl chloride ( $92 \mathrm{Da}$ ). This observation was further verified by performing the CID tandem mass spectrum of the deprotonated molecular adduct at $m / z 317$ (Fig. 7B) which produced two diagnostic product ions at $m / z 260$ and 225 . The product ion at $m / z 260$ is produced by the loss of one molecule of butene from the parent ion and is absent in the conventional ES MS, whereas the product ion at $m / z 225$ is produced by the loss of one molecule of butyl chloride (92 Da) from the parent ion.

The positive ion electrospray mass spectra of triphenyltin chloride $\underline{5}$ were recorded with focus voltages 20, 50 and $70 \mathrm{~V}$, and are shown in Fig. 8. In the ES MS recorded with a focus voltage of $20 \mathrm{~V}$, shown in Fig. 8A, a cluster of ions $[\mathrm{M}+\mathrm{H}-\mathrm{HCl}]^{+}$centered at 351 was assigned to the $\left[\mathrm{Ph}_{3} \mathrm{Sn}\right]^{+}$ion produced by the loss of a molecule of $\mathrm{HCl}$ from the protonated molecule, which is not observed. The ES MS of 4 , recorded with focus voltages of 50 and $70 \mathrm{~V}$, showed the presence of two additional fragment ions (Fig. 8B and C). The fragment ion cluster $\left[\mathrm{M}+\mathrm{HCl}-\mathrm{C}_{12} \mathrm{H}_{10}\right]^{+}$, centered around $m / z 197$, was assigned as $[\mathrm{PhSn}]^{+}$and was produced by the loss of a biphenyl molecule $(154 \mathrm{Da})$ from the $[\mathrm{M}+\mathrm{H}-\mathrm{HCl}]^{+}$ion at $\mathrm{m} / z 351$. As in the case of dibutyltin dichloride 2 , we again notice a reduction during fragmentation from a tetravalent tin cation to a divalent tin cation. More interesting, is the fragmentation of this $[\mathrm{M}+\mathrm{HCl}-$ $\left.\mathrm{C}_{12} \mathrm{H}_{10}\right]^{+}$ion by the loss of a radical phenyl group (77 Da) to afford the inorganic tin radical cation $[\mathrm{Sn}]^{+\cdot}$ at $m / z$ 120. Similar to bis-tributyltin oxide $\underline{1}$ and tributyltin chloride $\underline{2}$, the ES MS recorded at

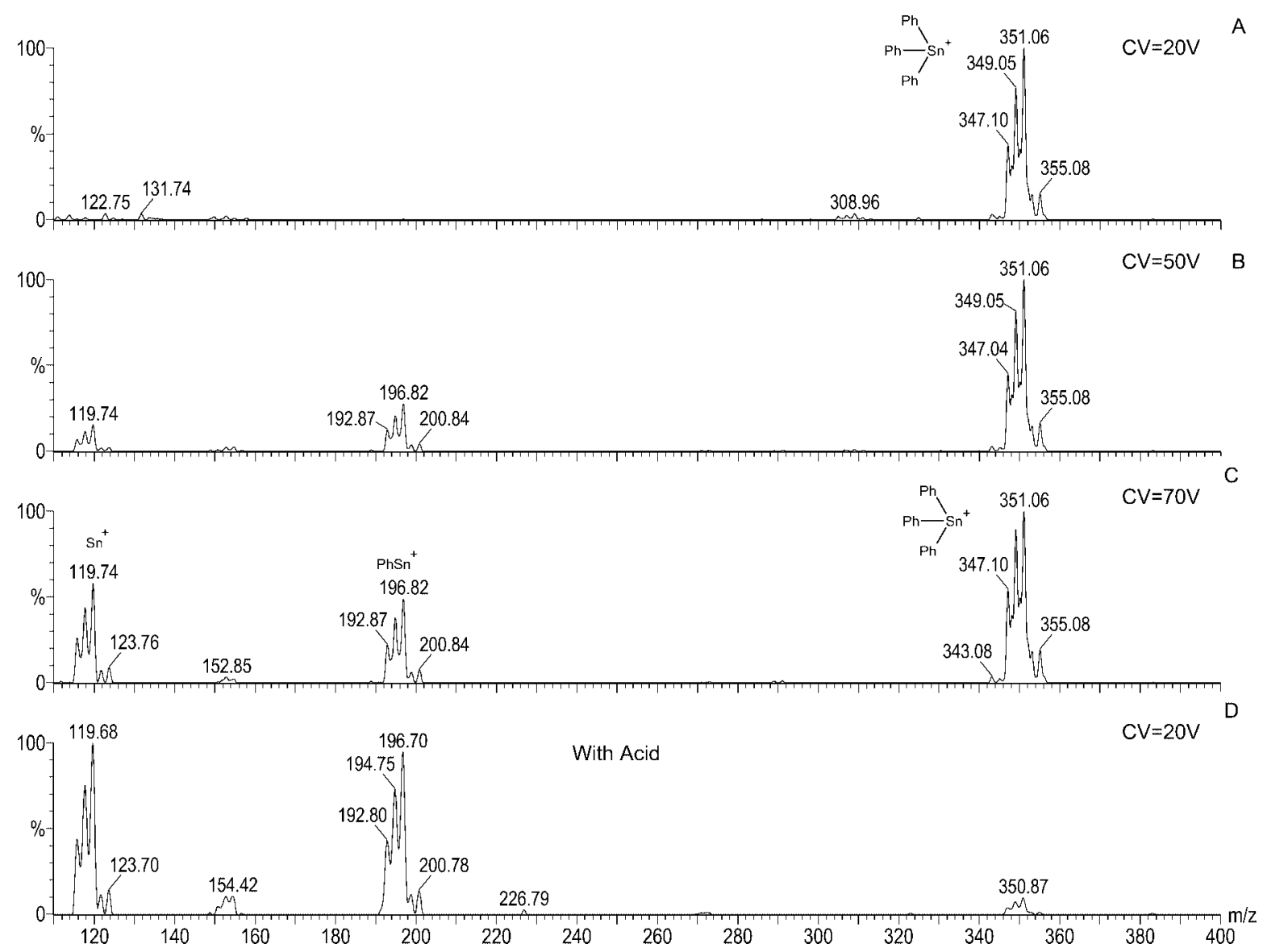

Fig. 8. Electrospray mass spectrum (positive ion mode) of triphenyltin chloride $\underline{5}$ recorded with different focus voltages: $\mathrm{CV}=$ $20 \mathrm{~V}(\mathrm{~A}), \mathrm{CV}=50 \mathrm{~V}(\mathrm{~B}), \mathrm{CV}=70 \mathrm{~V}(\mathrm{C})$, and in the presence of a trace of $6 \mathrm{M} \mathrm{HCl}$ at $\mathrm{CV}=20 \mathrm{~V}(\mathrm{D})$. 
a focus voltage of $20 \mathrm{~V}$ with a catalytic amount of $2 \mathrm{M} \mathrm{HCl}$, shown in Fig. 8D, indicated the complete disappearance of the $\left[\mathrm{Ph}_{3} \mathrm{Sn}\right]^{+}$ion at $m / z 351$ and the formation of the $[\mathrm{PhSn}]^{+}$ion cluster and the $[\mathrm{Sn}]^{+}$radical ion cluster centered around $\mathrm{m} / z 197$ and 120, respectively.

The CID tandem mass spectrum of the $\left[\mathrm{Ph}_{3} \mathrm{Sn}\right]^{+}$ion at $m / z$ 351, shown in Fig. 9A, gave the expected product ion $[\mathrm{PhSn}]^{+}$at $m / z$ 197, formed by the loss of a biphenyl molecule. In addition, the [Sn] ${ }^{+}$ radical ion at $m / z 120$ was produced either by the consecutive losses of a biphenyl molecule followed by a phenyl radical group from the $\left[\mathrm{Ph}_{3} \mathrm{Sn}\right]^{+}$ion, or by the loss of a phenyl radical group from the $[\mathrm{PhSn}]^{+}$ion at $m / z$ 197. These last observations were confirmed by obtaining the precursor ion scans of the $[\mathrm{Sn}]^{+} \cdot$ radical ion shown in Fig. 9B and the $[\mathrm{PhSn}]^{+}$ion shown in Fig. 9C. Indeed the precursor ion scan of the $[\mathrm{Sn}]^{+} \cdot$ radical ion at $m / z 130$ indicated that it was formed from both the $[\mathrm{PhSn}]^{+}$and $\left[\mathrm{Ph}_{3} \mathrm{Sn}\right]^{+}$fragment ions at $m / z 197$ and 351, respectively (Fig. 9B). Similarly, the precursor ion scan of the $[\mathrm{PhSn}]^{+}$fragment ion at $m / z 197$ showed that it originated from the $\left[\mathrm{Ph}_{3} \mathrm{Sn}\right]^{+}$fragment ion at $\mathrm{m} / z$ 351 (Fig. 9C).

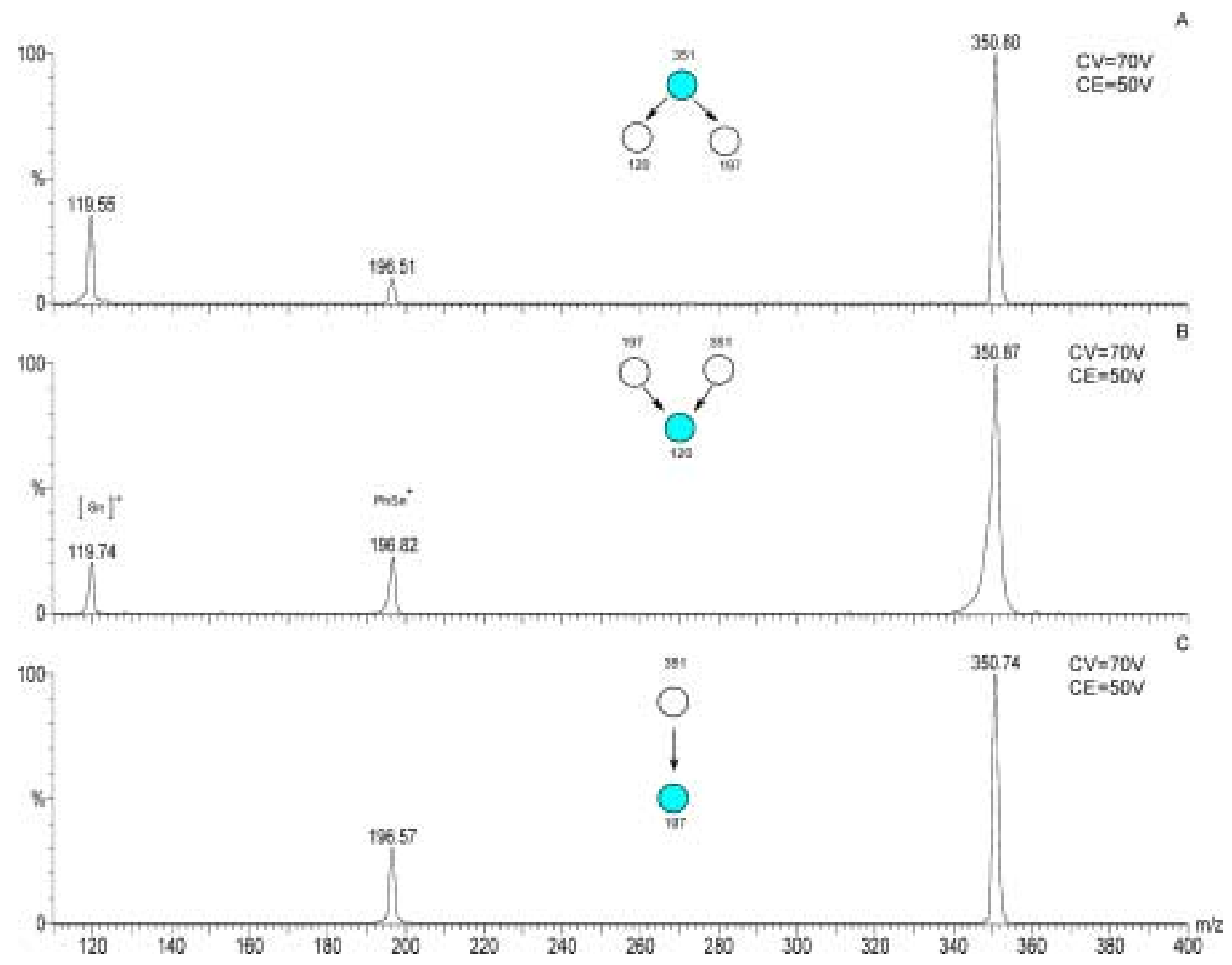

Fig. 9. CID tandem mass spectrum of the $\left[\mathrm{Ph}_{3} \mathrm{Sn}\right]^{+}$ion at $m / z 351$ (A); precursor ion scans of the [Sn] ${ }^{+} \cdot$ ion at $m / z 120$ (B) and the $[\mathrm{PhSn}]^{+}$ion at $m / z 197(\mathrm{C})$ recorded with $\mathrm{CV}=70 \mathrm{~V}$ and $\mathrm{CE}=50 \mathrm{~V}$. 


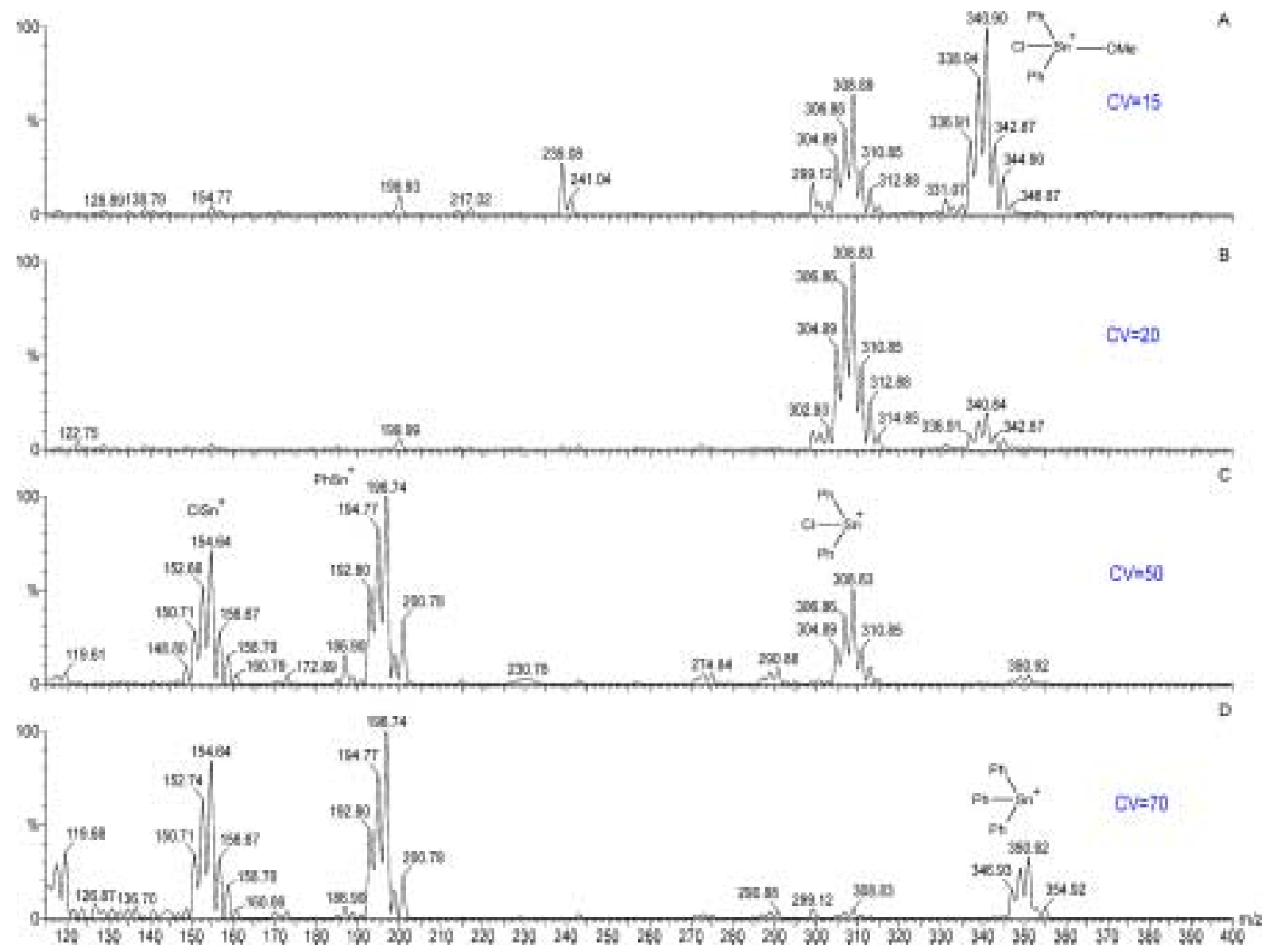

Fig. 10. Electrospray mass spectra of diphenyltin dichloride $\underline{6}$ recorded with different focus voltages: $\mathrm{CV}=15 \mathrm{~V}(\mathrm{~A}), \mathrm{CV}=$ $20 \mathrm{~V}(\mathrm{~B}), \mathrm{CV}=50 \mathrm{~V}(\mathrm{C})$ and $\mathrm{CV}=70 \mathrm{~V}(\mathrm{D})$.

The positive ion electrospray mass spectra of diphenyltin dichloride were recorded with focus voltages of 15, 20 and $50 \mathrm{~V}$ and are shown in Fig. 10. The ES MS of 4 when recorded with a focus voltage of $15 \mathrm{~V}$ showed two clusters of ions centered around $\mathrm{m} / z 341$ and 309 and is shown in Fig. 10A. The cluster of $[\mathrm{M}+\mathrm{H}+\mathrm{MeOH}-\mathrm{HCl}]^{+}$ions centered at $m / z 341$ was produced by the loss of a molecule of $\mathrm{HCl}$ from the protonated molecular adduct $[\mathrm{M}+\mathrm{H}+\mathrm{MeOH}]^{+}$at $m / z 378$ (which is not produced in this ES MS) and was assigned as $\left[\mathrm{Ph}_{2} \mathrm{ClSnOMe}\right]^{+}$. The $[\mathrm{M}+\mathrm{H}-\mathrm{HCl}]^{+}$ion centered at $m / z 309$ is formed by elimination of a molecule of methanol from the $\left[\mathrm{Ph}_{2} \mathrm{ClSnOMe}\right]^{+}$ion and was assigned as the $\left[\mathrm{Ph}_{2} \mathrm{SnCl}\right]^{+}$ion.

When the focus voltage was increased to $20 \mathrm{~V}$ (Fig. 10B) we observed an increase in intensity of the $\left[\mathrm{Ph}_{2} \mathrm{SnCl}\right]^{+}$fragment ion at $m / z 309$ and the reduction in intensity of the $\left[\mathrm{Ph}_{2} \mathrm{ClSnOMe}\right]^{+}$fragment ion. In the ES MS of $\underline{5}$, recorded with a focus voltage of $50 \mathrm{~V}$ (Fig. 10C) we notice the absence of the $\left[\mathrm{Ph}_{2} \mathrm{OMeSnCl}\right]^{+}$ion at $m / z 341$ and the formation of the $\left[\mathrm{Ph}_{2} \mathrm{SnCl}\right]^{+}$ion at $m / z 309$ in addition to the divalent $[\mathrm{PhSn}]^{+}$ion at $\mathrm{m} / z 197$ formed by the loss of a molecule of phenyl chloride (113 Da) from the $\left[\mathrm{Ph}_{2} \mathrm{SnCl}\right]^{+}$ion. We also observed the formation of the divalent $[\mathrm{SnCl}]^{+}$ion at $m / z 155$ formed by the loss of a diphenyl molecule $(154 \mathrm{Da})$ from the $\left[\mathrm{Ph}_{2} \mathrm{SnCl}\right]^{+}$ion. The divalent ions at $m / z 197$ and 155 may lose either a phenyl or chlorine radical to afford the inorganic tin radical ion [Sn] ${ }^{+\cdot}$ at $m / z 120$. Surprisingly, in this ES MS, we also noticed the presence of a cluster of ions around $m / z 351$, which 
correspond to the $\left[\mathrm{Ph}_{3} \mathrm{Sn}\right]^{+}$ion of triphenyltin chloride. As this ion cluster was not observed in the ES MS of $\underline{5}$ recorded with a focus voltage of $20 \mathrm{~V}$, we tentatively proposed that a disproportionation of the $\left[\mathrm{Ph}_{2} \mathrm{SnCl}\right]^{+}$ion into the $\left[\mathrm{Ph}_{3} \mathrm{Sn}\right]^{+}$occurred during the electrospray ionization process at higher focus voltages. To probe this hypothesis further, we recorded the ES MS of $\underline{5}$ with a focus voltage of $70 \mathrm{~V}$ as shown in Fig. 10D and observed that the quantity of $\left[\mathrm{Ph}_{3} \mathrm{Sn}\right]^{+}$at $\mathrm{m} / z 351 \mathrm{did}$, indeed, increase.

The CID tandem mass spectrum of the $\left[\mathrm{Ph}_{2} \mathrm{OMeSnCl}\right]^{+}$ion at $m / z 341$ was recorded as shown in Fig. 11A and produced a series of diagnostic product ions at $m / z 309,197,155$ and 120, which are present in the conventional ES MS. Similarly, the CID tandem mass spectrum of the $\left[\mathrm{Ph}_{2} \mathrm{SnCl}^{+}\right.$ion at $m / z 309$ produced the expected series of product ions $[\mathrm{PhSn}]^{+},[\mathrm{SnCl}]^{+}$and $[\mathrm{Sn}]^{+\cdot}$ at $m / z 197,155$ and 120, respectively, as shown in Fig. 11B. The CID tandem mass spectrum of the precursor ion $\left[\mathrm{Ph}_{3} \mathrm{Sn}\right]^{+}$ at $m / z$ 351, shown in Fig. 11C, which was formed from diphenyltin dichloride $\underline{5}$, is identical to the one reported in Fig. 9A and confirms the presence of ion $\underline{5}$ which could only be derived from the triphenyltin cation.

The positive ion electrospray mass spectra of monophenyltin trichloride $\underline{7}$ were recorded with focus voltages of 20 and $30 \mathrm{~V}$ and are shown in Fig. 12. The ES MS recorded with a focus voltage of

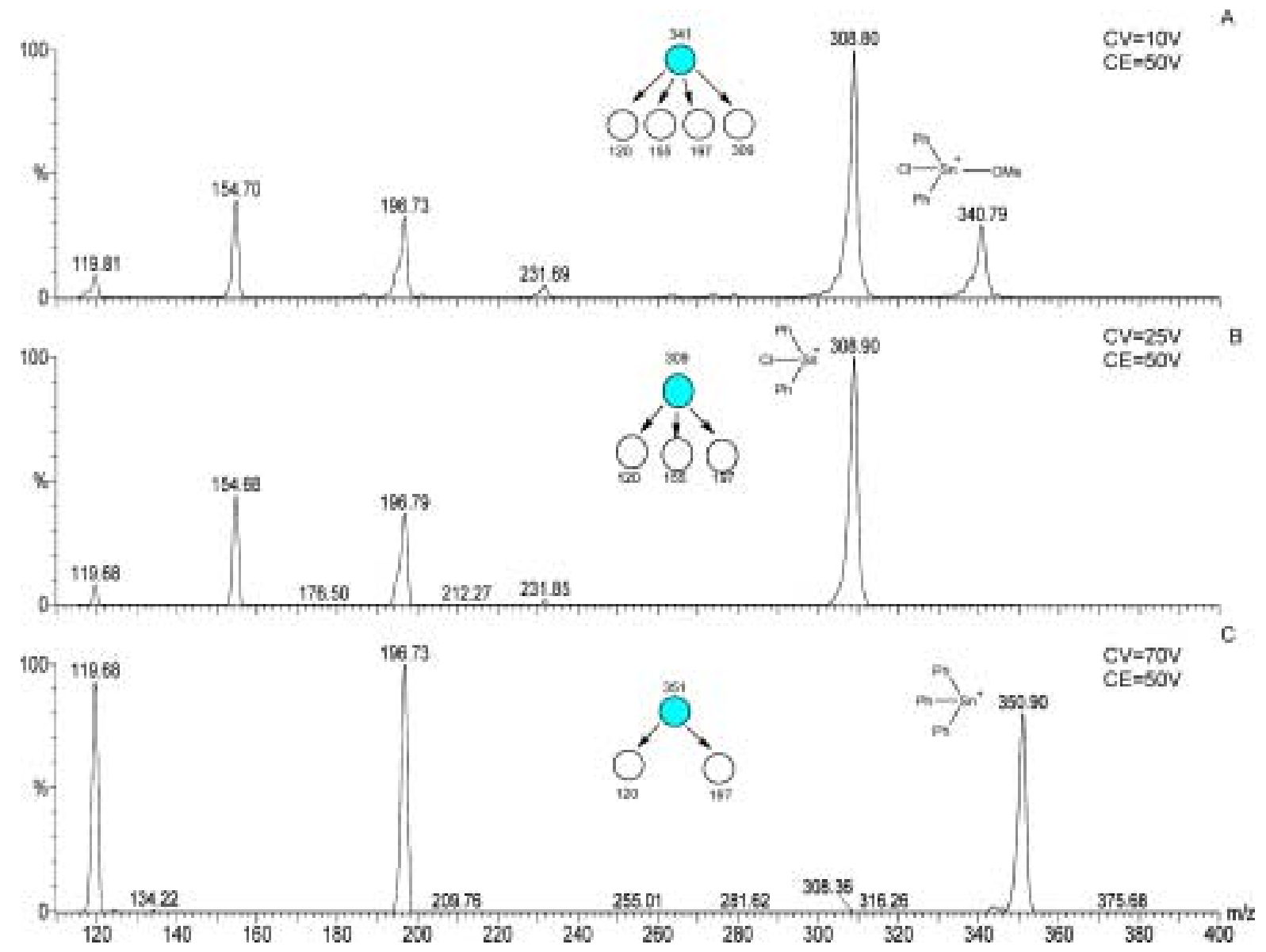

Fig. 11. CID tandem mass spectra of the $\left[\mathrm{Ph}_{2} \mathrm{OMeSnCl}\right]^{+}$ion at $m / z 341$ (A), the $\left[\mathrm{Ph}_{2} \mathrm{SnCl}^{+}\right.$ion at $m / z 309$ (B) and the $\left[\mathrm{Ph}_{3} \mathrm{Sn}\right]^{+}$ion at $m / z 351$ obtained from diphenyltin dichloride $(\mathrm{C})$ and recorded with a $\mathrm{CV}=70 \mathrm{~V}$ and $\mathrm{CE}=50 \mathrm{~V}$. 


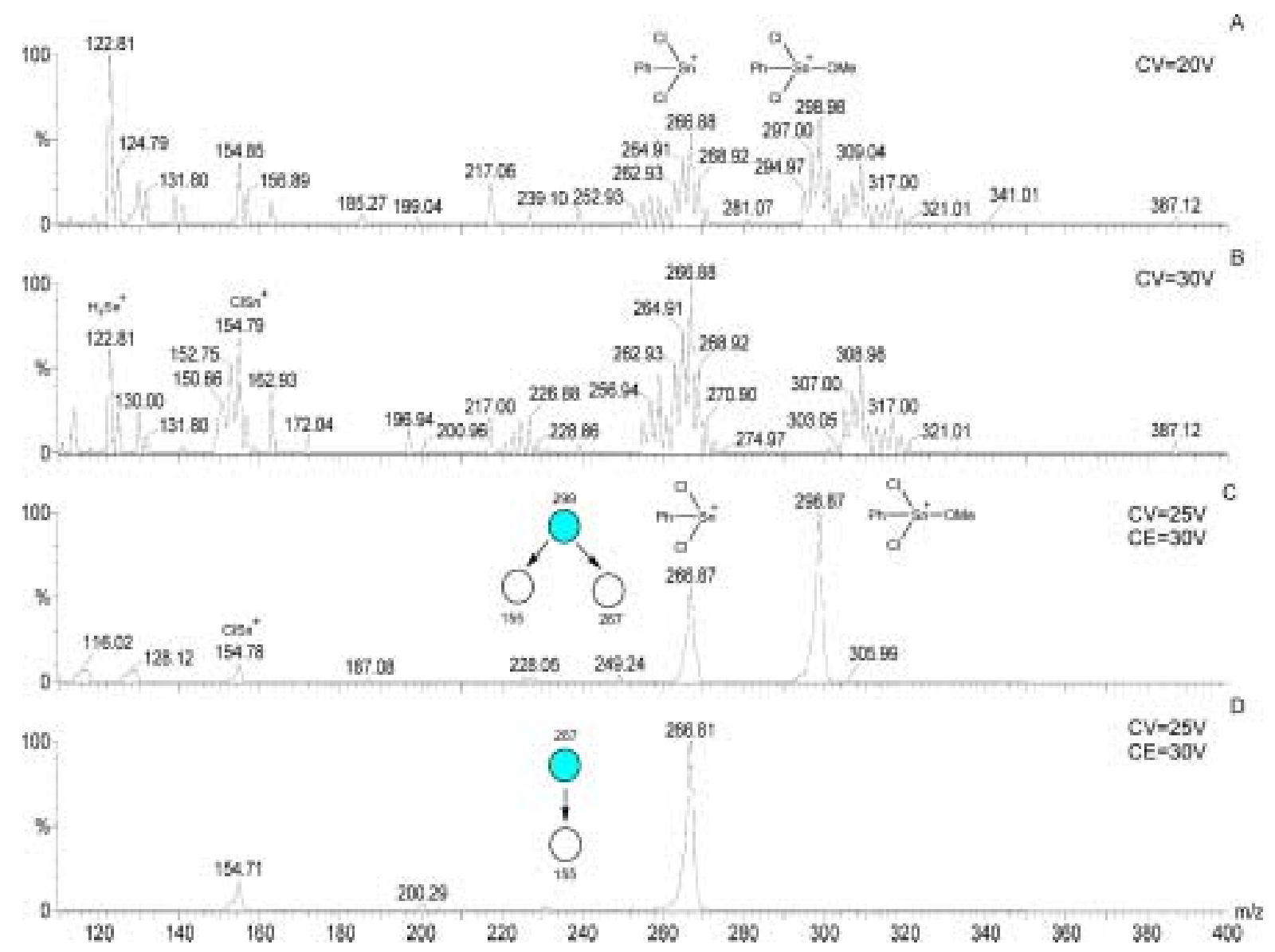

Fig. 12. Electrospray mass spectra of monophenyltin trichloride $\underline{7}$ recorded with different focus voltages: $\mathrm{CV}=20 \mathrm{~V}$ (A), $\mathrm{CV}=30 \mathrm{~V}(\mathrm{~B})$ and $\mathrm{CID}$ tandem mass spectra of the $\left[\mathrm{PhOMeSnCl}_{2}\right]^{+}$ion at $m / z 299(\mathrm{C})$ and the $\left[\mathrm{PhSnCl}_{2}\right]^{+}$ion at $m / z 267$ (D) recorded with a $\mathrm{CV}=25 \mathrm{~V}$ and $\mathrm{CE}=30 \mathrm{~V}$.

$20 \mathrm{~V}$, shown in Fig. 12A, indicates the presence of the tin cluster of the $[\mathrm{M}+\mathrm{H}+\mathrm{MeOH}-\mathrm{HCl}]^{+}$ions centered at $m / z 299$, assigned as $\left[\mathrm{Cl}_{2} \mathrm{PhSnOMe}\right]^{+}$formed by the elimination of a molecule of $\mathrm{HCl}$ from the protonated molecular adduct $[\mathrm{M}+\mathrm{H}+\mathrm{MeOH}]^{+}$at $m / z 378$ (which is absent in this ES MS). We also noticed the presence of the cluster of $\left[\mathrm{Ph}_{2} \mathrm{SnCl}\right]^{+}$ions centered around $m / z 309$, which appears to indicate that during the electrospray ionization process, a small disproportionation reaction of monophenyltin trichloride $\underline{1}$ into diphenyltin dichloride $\underline{6}$ must have occurred. It is worthwhile to mention that the monophenyltin trichloride used was assessed as being $99.90 \%$ pure. The cluster of $[\mathrm{M}+\mathrm{H}-\mathrm{HCl}]^{+}$ fragment ions centered around $m / z 267$ is produced by the loss of a molecule of methanol from the ion at $m / z 299$ and was assigned accordingly as $\left[\mathrm{Cl}_{2} \mathrm{SnPh}\right]^{+}$. In the ES MS of $\underline{7}$, recorded with a focus voltage of $20 \mathrm{~V}$ and shown in Fig. $12 \mathrm{~B}$, the intensities of the $\left[\mathrm{Ph}_{2} \mathrm{SnCl}\right]^{+}$and $\left[\mathrm{Cl}_{2} \mathrm{SnPh}\right]^{+}$ions at $\mathrm{m} / z 309$ and 267, respectively, have increased, whereas the $\left[\mathrm{Cl}_{2} \mathrm{PhSnOMe}\right]^{+}$fragment at $\mathrm{m} / z 299$ has completely fragmented to lower mass ions. We also observed the presence of the divalent $[\mathrm{SnCl}]^{+}$fragment ion at $m / z 155$, formed by the loss of a molecule of phenyl chloride (113 Da) from the $\left[\mathrm{Cl}_{2} \mathrm{SnPh}\right]^{+}$ion at $\mathrm{m} / z$ 267 and reduction from a tetravalent tin cation to a divalent tin cation. 
The CID tandem mass spectrum of the $[\mathrm{M}+\mathrm{H}+\mathrm{MeOH}-\mathrm{HCl}]^{+}$ion at $m / z 299$ is shown in Fig. 12C and indicates, as expected, the formation of the product ions $\left[\mathrm{Cl}_{2} \mathrm{SnPh}\right]^{+}$and $[\mathrm{SnCl}]^{+}$at $\mathrm{m} / z 267$ and 155 , respectively. This formation has already been rationalized in the previous section. Similarly, the $\mathrm{CID}$ tandem mass spectrum of the $[\mathrm{M}+\mathrm{H}-\mathrm{HCl}]^{+}$ion at $m / z 267$ indicates the formation of the product ion $[\mathrm{SnCl}]^{+}$at $m / z 155$.

For quantification of organotin compounds in real life samples (e.g., sediment extracts), the use of MRM of low energy CID tandem mass spectrometric analysis becomes imperative, especially when no prior separation of the analytes is performed. As already reported by Siu and coworkers [33,34], we have noted that the use of single ion monitoring (SIM) ES MS for a sample as complex as a sediment extract is not recommended, due to the fact that the spectrum usually contains ions from low to high masses including those with $m / z$ characteristic of the $\mathrm{R}_{n} \mathrm{SnX}_{4-n}$ analytes. This is rather disconcerting, especially when we used standard sediment materials which lacked organotin analytes. The use of MRM analysis overcomes this problem since only parent ion/product ion transitions are monitored and counted. Therefore, as a result of this process, no liquid chromatographic process (offline or online) is needed following sediment extraction. This is extremely convenient since, as indicated by Siu et al., some reverse phase LC materials have been observed to cause degradation of the organotin analytes (especially TBT) and bypassing LC eliminates this potential problem [35,38]. Recently, LC with fluorometric detection using fisetin as a fluorogenic reagent was reported. Unfortunately, this method, which involves extraction with ethyl acetate in a hydrochloric acid medium, is capable of detecting only tributyltin and triphenyltin analytes [39].

For the quantification of bis-tributyltin oxide 1 in real life sediment samples, MRM (in the positive ion mode) of the low energy collision $(\mathrm{CE}=30 \mathrm{~V}) \mathrm{CID}$ tandem mass spectrometric transition of parent/product ion pairs $599 \rightarrow 291,599 \rightarrow 235$ and $599 \rightarrow 179$ were used. For the MRM analysis of tributyltin chloride $\underline{2}(\mathrm{CE}=26 \mathrm{~V})$, the transition of parent/product ion pairs $291 \rightarrow 235,291 \rightarrow 179$, $235 \rightarrow 179,235 \rightarrow 123$ and $179 \rightarrow 123$ were used. The MRM analysis of the dibutyltin dichloride $\underline{3}$ (CE $=29 \mathrm{~V}$ ) involved the following parent/product ion pair transitions: $269 \rightarrow 213,269 \rightarrow 177,269 \rightarrow 155$, $269 \rightarrow 121,213 \rightarrow 177$ and $213 \rightarrow 121$. The MRM of triphenyltin chloride $\underline{5}(\mathrm{CE}=50 \mathrm{~V})$ involved the following parent/product ion transitions: $351 \rightarrow 197$ and $351 \rightarrow 120$. The MRM analysis of diphenyltin dichloride $\underline{6}(\mathrm{CE}=50 \mathrm{~V})$ involved the parent/product ion pair transitions $341 \rightarrow 309,341 \rightarrow 197$, $309 \rightarrow 197,309 \rightarrow 155$ and $309 \rightarrow 120$. The MRM analysis of the monophenyltin trichloride $(\mathrm{CE}=$ $30 \mathrm{~V}$ ) involved the following parent/product ion pairs: $298 \rightarrow 267,298 \rightarrow 155$ and $267 \rightarrow 155$. The quantification of monobutyltin trichloride $\underline{4}$ was achieved using low energy collision CID tandem mass spectrometric transition in the negative mode. MRM analysis $(\mathrm{CE}=50 \mathrm{~V})$ involved the parent/product ion pair transition $313 \rightarrow 221$.

The determination of organotin compounds using electrospray tandem mass spectrometry is a very simple and efficient method. The sample extraction and work-up can be accomplished in about two hours and at three injections every five minutes, the analysis itself is extremely fast. The only inconvenience is the fact that for each type of organotin, separate specific MRM transitions have to be monitored for each individual analyte. This necessitates multiple injections for each analyte to be determined since mass selected ions of each species are produced at different focus voltages and the fragment ion spectra of mass selected parent/product ions require different collision energies.

The accuracy of this method is demonstrated in Table 1, which shows the agreement of the determined values of the PACS-2 reference sediment with the certified values.

There is a plethora of references in the literature suggesting the use of various solvents mixed with hydrochloric acid (concentration varying from 2 to $10 \mathrm{M}$ ) and complexing agents for the extraction of 
Table 1

Organobutyltin compound determination in PACS-2 ( $\mu \mathrm{g} \mathrm{Sn} / \mathrm{g}$ sediment)

\begin{tabular}{lccc}
\hline & \multicolumn{2}{c}{ ES MS/MS values } & Certified values \\
\hline Tributyltin & $0.96 \pm 0.88^{\mathrm{a}}$ & $(6)^{\mathrm{b}}$ & $0.98 \pm 0.13$ \\
Dibutyltin & $1.07 \pm 0.87$ & $(7)$ & $1.09 \pm 0.15$ \\
Monobutyltin & $0.41 \pm 0.21$ & $(5)$ & $0.45 \pm 0.12$ \\
\hline
\end{tabular}

${ }^{a}$ Standard deviation.

${ }^{\mathrm{b}}$ Number of replicate analyses.

organotin compounds from solid samples such as sediment, soil or sludge [40-42]. We have shown that in the ES MS of all organotin compounds, treatment with either a high or low concentration of hydrochloric acid results in a loss of all butyl or phenyl groups. Similarly, we observed that when any of several series of mixed organotin compounds were subjected to acidification-complexation, followed by trans-alkylation derivatization with alkylmagnesium bromide Grignard reagent, we were not successful in the identification and determination or separation of any resulting diagnostic parent/product ion pair produced by MRM of GC-EI/CI MS/MS analyses. This, once more, confirms that decomposition of the analytes has probably occurred during the acid treatment.

We would like to point out that the organobutyltin $\mathrm{R}_{n} \mathrm{SnX}_{4-n}$ compounds present in the reference sediment materials PACS-1 and PACS-2 exist in the chloride form (i.e. $\mathrm{X}=\mathrm{Cl}$ ). This was proven by using metastable atom bombardment (MAB) ionization mass spectrometry which produced the $\left[\mathrm{R}_{n} \mathrm{SnX}_{4-n}\right]^{+ \text {. }}$ molecular radical ion which was further analyzed by low energy CID-tandem mass spectrometry. These results will be the subject of a future publication.

This rationale has described the measurement of organotins using electrospray low collision energy tandem mass spectrometry. The method presented herein has proven to be a sensitive and facile method for the analysis of TBTX, DBTX 2 and $\mathrm{MBTX}_{3}$ which requires no chromatographic separation or chemical modification. This tremendously simplifies sample workup since detection is of the unmodified organotin compounds. The absolute detection limit for TBTX was about $1 \mathrm{pg}$ of $\mathrm{Sn}$ in the absence of matrix interference. No MRM CID tandem mass spectrometric analysis of TPTX, DTPX 2 and MPTX 3 was performed on certified reference sediment due to the lack of such material. However, the presence and quantification of these compounds were established in a Quasimeme II reference material which is not certified. In conclusion, the present method offers a simple and attractive alternative to all previously reported analytical methods for the measurement of organotin compounds.

\section{Acknowledgement}

The authors acknowledge the financial support of the Department of Fisheries and Oceans, Environmental Science Program.

\section{References}

[1] N. Voulvoulis, M.D. Scrimshaw and J.N. Lester, Appl. Organometal. Chem. 13 (1999), 135-143.

[2] D. Liu, R.J. McGuire, Y.L. Lau, G.J. Paccpavicius, H. Okamura and I. Aoyama, Mat. Res. 31 (1997), 2363.

[3] S.J. de Mora, Tributyltin: Case Study of an Environmental Contaminant, Cambridge University Press, Cambridge, 1996, Vol. 8 and references cited therein.

[4] R.R. Wilkinson, Neurotoxicology 5 (1984), 141-158.

[5] R.J. McGuire, Water Qual. Res. J. Can. 35 (2000), 633-699. 
[6] P.H. Dowson, J.M. Bubb and J.N. Lester, Water Sci. Technol. 28 (1993), 133.

[7] Y.K. Chau, R.J. McGuire, M. Brown, F. Yang and S.P. Batchelor, Water Qual. Res. J. Can. 32 (1997), 453.

[8] I.M. Davies, M.J.C. Harding, S.K. Bailey, A.M. Shanks and R. Länge, Mar. Ecol. Progr. Ser. 158 (1997), 191-204.

[9] E.A. Dyrynda, Mar. Pollut. Bull. 24 (1992), 156-163.

[10] M.M.M. Law, Arch. Environ. Contam. Toxicol. 20 (1991), 299.

[11] M. Abalos, J.M. Bayona, R. Compañó, M. Granados, C. Leal and M.D. Prat, J. Chromatogr. A 788 (1997), 1-49.

[12] J.I.G. Alonso, J.R. Encinar, I.L. Granadillo, R.G. Fernandez, M.M. Bayón and A. Sanz-Medel, Trace metal speciation in environmental analysis using inductively coupled mass spectrometry, in: Advances in Mass Spectrometry, E. Gelpi, ed., John Wiley and Sons Ltd., Baffins Lane, Chichester, West Sussex, UK, 2001, Vol. 15, pp. 265-281.

[13] J.K. Kacprzak, Int. J. Environ. Anal. Chem. 38 (1990), 561.

[14] W.A. Aue and Ch.G. Flinn, Anal. Chem. 52 (1980), 1537-1538.

[15] O.F.X. Donard, B. Latère, F. Martin and R. Lobinski, Anal. Chem. 67 (1995), 4250-4254.

[16] H.A. Meinema, T. Burger-Wiersma, G. Versluis-de Haan and E.Ch. Gevers, Environ. Sci. Technol. 12 (1978), $288-293$.

[17] J. Greaves and M.A. Unger, Biomed. Mass Spectrom. 15 (1988), 565-569.

[18] I. Tolosa, J.M. Bayona, J. Albaigés, L.F. Alemcastro and J. Tarradellas, Fresenius J. Anal. Chem. 339 (1991), $646-653$.

[19] F.M. Martin and O.F.X. Donard, J. Anal. Atom. Spectrom. 19 (1996), 1143-1151.

[20] P. Michel and B. Averty, Appl. Organomet. Chem. 5 (1991), 393-397.

[21] M.D. Muller, Anal. Chem. 59 (1987), 617-623.

[22] C.G. Arnold, M. Berg, S.R. Müller, U. Domman and R. Schwarzenbach, Anal. Chem. 70 (1998), 3094-3101.

[23] J.B. Fenn, M. Mann, C.K. Meng, S.F. Wong and C.M. Withehouse, Science 246 (1989), 64-71.

[24] J. Banoub, E. Gentil and J. Kiceniuk, Int. J. Environ. Anal. Chem. 61 (1995), 1-26.

[25] J. Banoub, E. Gentil and J. Kiceniuk, Int. J. Environ. Anal. Chem. 61 (1995), 143-167.

[26] J.H. Banoub, R. Martin, H.J. Hodder, G. Sheppard and S. Sharpe, Analusis 2 (1997), 15-19.

[27] J. Hellou, D. MacKay and J. Banoub, Chemosphere 38, 457-473.

[28] J. Banoub, S. Combden, J. Miller-Banoub, G. Sheppard and H. Hodder, Nucleosides and Nucleotides 18 (1999), $2751-$ 2768.

[29] J.H. Banoub, J.E. Miller-Banoub, G.V. Sheppard and H.J. Hodder, Analytical measurement of organotin compounds by tandem mass spectrometry methods: discrepancies and solutions, in: Advances in Mass Spectrometry, Environmental and Forensic Analysis by Mass Spectrometry, E. Gelpi, ed., John Wiley and Sons Ltd., Baffins Lane, Chichester, West Sussex, UK, 2001, Vol. 15, pp. 859-860.

[30] K.M.W. Siu, G.J. Gardner and S.S. Berman, Rapid Commun. Mass Spectrom. 2 (1988), 201.

[31] G. Lawson and N. Ostah, Appl. Organometal. Chem. 8 (1994), 525-532.

[32] T.L. Jones and L.D. Betowski, Rapid Commun. Mass Spectrom. 7 (1993), 1003-1008.

[33] G. Lawson, E.D. Woodland, T. Jones and T. Wilson, Appl. Organometal. Chem. 10 (1996), 135-143.

[34] K.M.W. Siu, G.J. Gardner and S.S. Berman, Anal. Chem. 61 (1989), 2330-2322.

[35] K.M.W. Siu, J.W. McLaren, P.S. Maxwell, G.J. Gardner and S.S. Berman, Applied Chemistry of Butyltins, Oceans 88, Baltimore, MD, November 1988

[36] F.W. McLafferty, Tandem Mass Spectrometry, Wiley Interscience, New York, 1993, p. 506.

[37] K.L. Busch, G.L. Glish and S.A. McLuckey, Mass Spectrometry/Mass Spectrometry: Techniques and Applications of Tandem Mass Spectrometry, CVCH, New York, 1988, p. 337.

[38] K.L. Jewett and F.E. Brinckman, J. Chromatogr. Sci. 19 (1981), 583-593.

[39] C. Leal, M. Granados, R. Campañó and M.D. Prat, J. Chromatogr. A 809 (1998), 39-41.

[40] M.A. Unger, W.G. MacIntyre, J. Graves and R.J. Hugget, Chemosphere 13 (1986), 462.

[41] Y.K. Chau, S. Zhang and R.J. MaGuire, Analyst 117 (1992), 1161-1164.

[42] S. Zhang, Y.K. Chau, N.C. Li and A.S.Y. Chau, Appl. Organometal. Chem. 5 (1991), 431.

[43] P. Quevallier, M. Astruc, L. Ebdon, G.N. Kramer and B. Griepink, Appl. Organometal. Chem. 8 (1994), 639-644. 


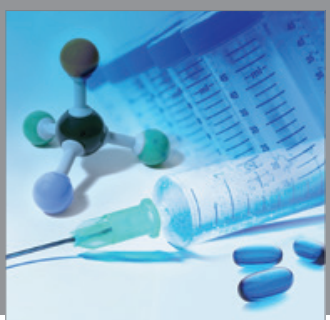

International Journal of

Medicinal Chemistry

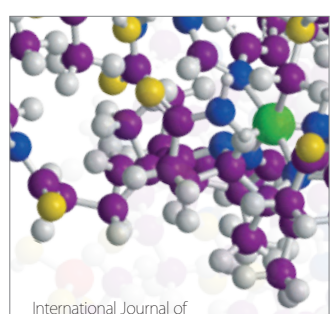

Carbohydrate Chemistry

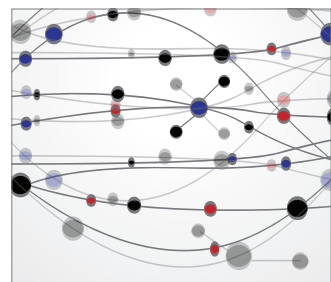

The Scientific World Journal
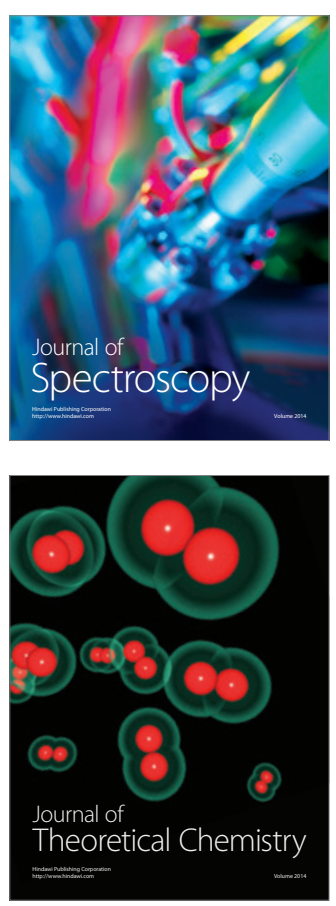
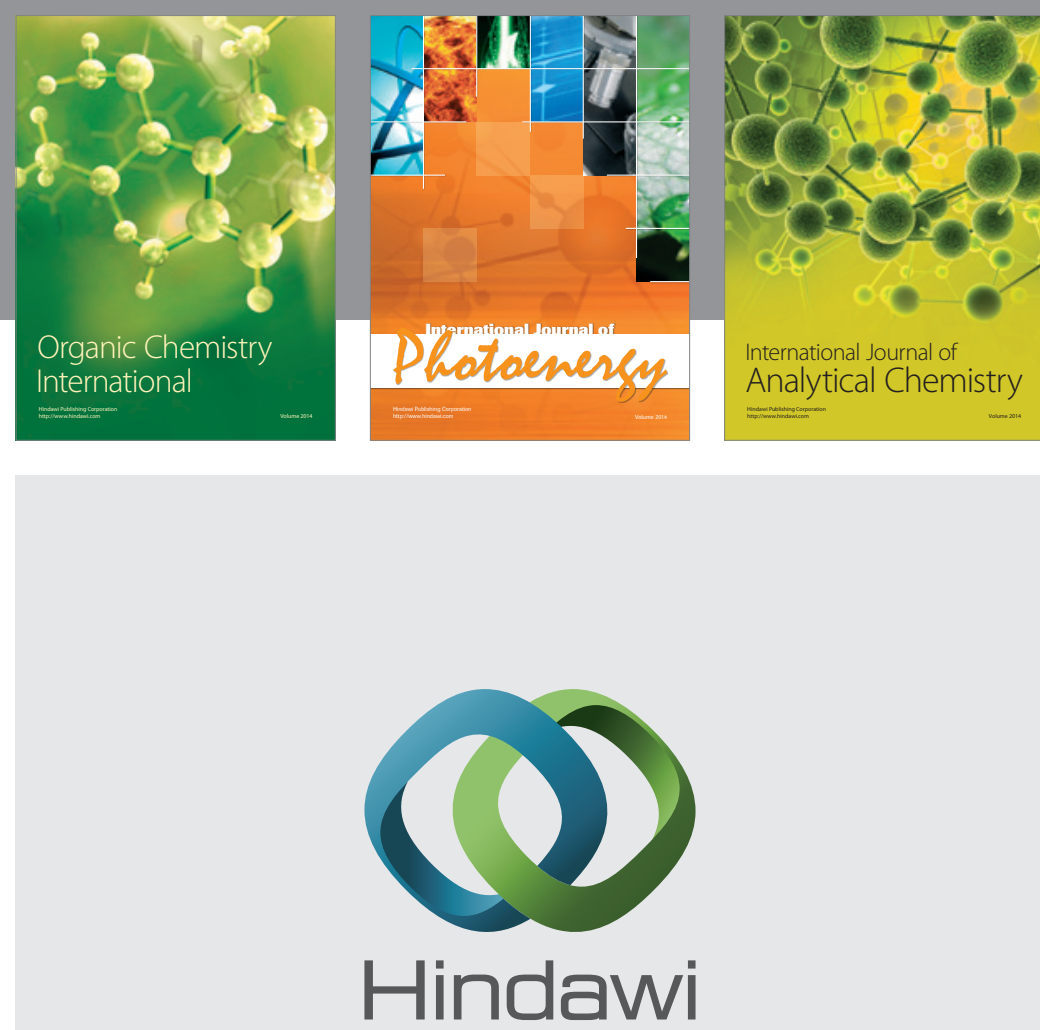

Submit your manuscripts at

http://www.hindawi.com
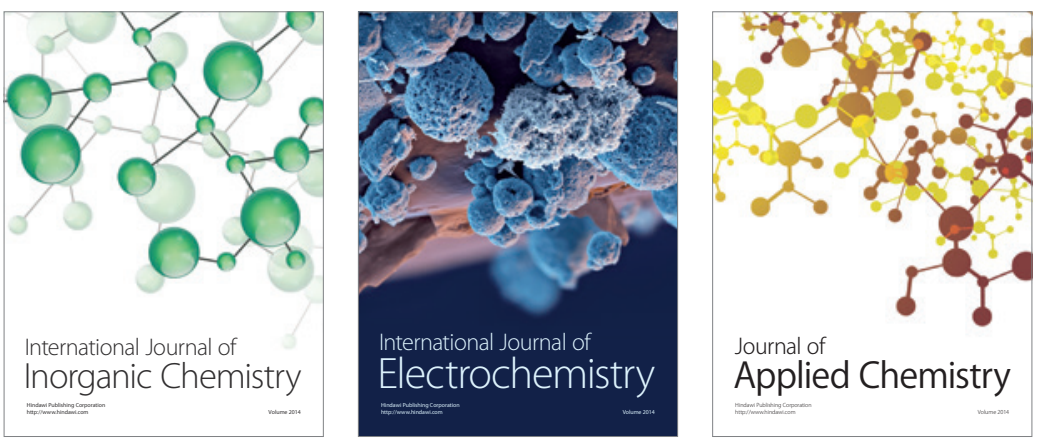

Journal of

Applied Chemistry
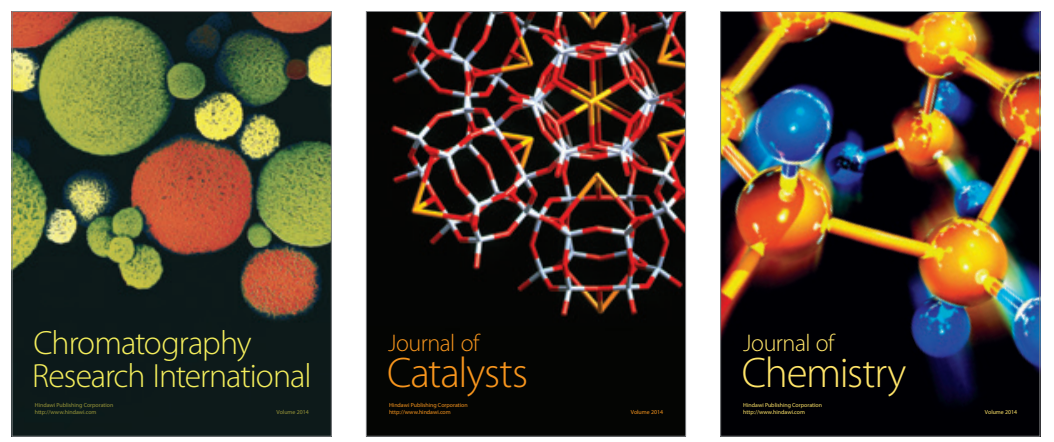
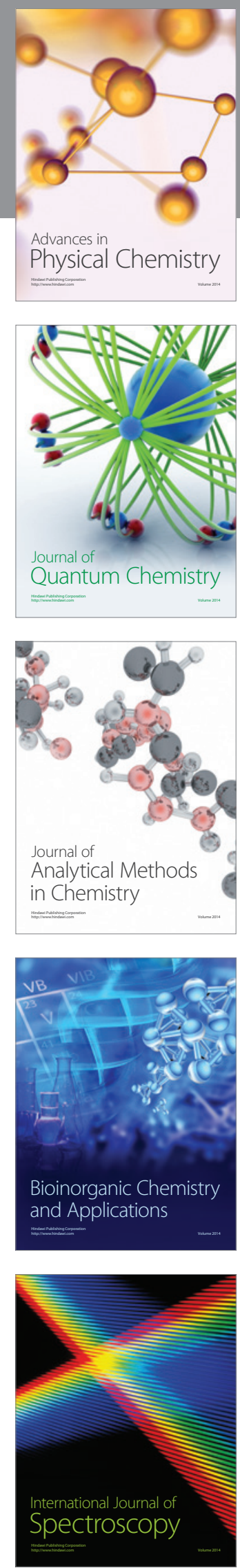